\title{
Pandemia covid-19: o caráter emergencial das transferências de renda direta e indireta para a população vulnerável do estado de Goiás
}

Covid-19 pandemic: the emergency nature of direct and indirect income transfers to the vulnerable population of the state of Goiás Pandémie covid-19: le caractère urgent des transferts de revenus direct et indirect vers la population vulnérable de l'état de Goiás, Brésil Pandemia covid-19: el carácter de emergencia de las transferencias de renta directa e indirecta para la población vulnerable del estado de Goiás

Tadeu Alencar Arrais, Adriano Rodrigues de Oliveira, Diego Pinheiro Alencar, Tathiana Rodrigues Salgado, Juheina Lacerda Viana e Amanda Fernandes Miranda

\section{(2) OpenEdition}

\section{Journals}

Edição electrónica

URL: http://journals.openedition.org/espacoeconomia/13734

DOI: 10.4000/espacoeconomia.13734

ISSN: 2317-7837

Editora

Núcleo de Pesquisa Espaço \& Economia

Refêrencia eletrónica

Tadeu Alencar Arrais, Adriano Rodrigues de Oliveira, Diego Pinheiro Alencar, Tathiana Rodrigues Salgado, Juheina Lacerda Viana e Amanda Fernandes Miranda, « Pandemia covid-19: o caráter emergencial das transferências de renda direta e indireta para a população vulnerável do estado de Goiás », Espaço e Economia [Online], 18 | 2020, posto online no dia 23 abril 2020, consultado o 20 maio 2020. URL : http://journals.openedition.org/espacoeconomia/13734; DOI : https://doi.org/10.4000/ espacoeconomia. 13734

Este documento foi criado de forma automática no dia 20 maio 2020

(c) NUPEE 


\section{Pandemia covid-19: o caráter emergencial das transferências de renda direta e indireta para a população vulnerável do estado de Goiás}

Covid-19 pandemic: the emergency nature of direct and indirect income transfers to the vulnerable population of the state of Goiás Pandémie covid-19: le caractère urgent des transferts de revenus direct et indirect vers la population vulnérable de l'état de Goiás, Brésil Pandemia covid-19: el carácter de emergencia de las transferencias de renta directa e indirecta para la población vulnerable del estado de Goiás

Tadeu Alencar Arrais, Adriano Rodrigues de Oliveira, Diego Pinheiro Alencar, Tathiana Rodrigues Salgado, Juheina Lacerda Viana e Amanda Fernandes Miranda

Esta crônica chega ao fim. É tempo de o doutor Bernard Rieux confessar que é o seu autor. Mas, antes de narrar os últimos acontecimentos, ele gostaria, ao menos, de justificar a sua intervenção e fazer compreender por que quis assumir o tom de testemunha objetiva. Ao longo de toda duração da peste, sua profissão o colocou em condições de ver a maior parte dos seus concidadãos e de recolher os seus sentimentos. Estava, pois, em boa posição para narrar o que tinha visto e ouvido. De uma maneira geral, esforçou-se no sentido de não contar mais coisas do que pôde 
ver, de não atribuir aos companheiros de peste pensamentos que, afinal, eles não eram obrigados

a formular e de utilizar apenas os textos que o acaso ou desgraça lhe tinham posto em mãos.

Albert Camus, A Peste, p. 208.

A segurança protetora é necessária para proporcionar uma rede de segurança social, impedindo que a população afetada seja reduzida à miséria abjeta e, em alguns casos, até mesmo à fome e à morte. A esfera da segurança protetora inclui disposições institucionais fixas, como benefícios aos desempregados e suplementos de renda regulamentares para os indigentes, bem como medidas ad hoc, como distribuição de alimentos em crises de fomes coletiva ou empregos públicos de emergência para gerar renda para os necessitados. Amartya Sen, Desenvolvimento como liberdade, p. 57.

\section{Introdução}

1 O ano de 2020 se iniciou com um grande desafio para a humanidade: mitigar os efeitos de uma pandemia para a já combalida economia mundial. No apagar das luzes de 2019, em 31 de dezembro, a cidade Wuhan, localizada na província de Hubei (China), alerta a Organização Mundial de Saúde (OMS) sobre a proliferação de casos de pneumonia, decorrente de um vírus até então não registrado em seres humanos. No limiar de janeiro, as autoridades chinesas identificam um novo tipo de Coronavírus, que, como os antecessores, comprometia o sistema respiratório se caracterizando como um tipo de SARS (Síndrome Respiratória Aguda Grave, inicialmente nomeado como 2019-nCoV, em 11 de fevereiro recebeu o nome de SARS-CoV-2). Esse novo Coronavírus passa a ser caracterizado como o responsável pela proliferação da doença COVID-19 (OMS, 2020).

O impacto da evolução, na escala nacional, dos casos de Coronavírus (COVID-19), é motivo de preocupação de estudiosos de várias áreas do conhecimento. A projeção das demandas de infraestrutura médico-hospitalar, associada aos cenários de evolução geométrica da doença, exige um esforço de especialistas em saúde pública, da comunidade científica e, especialmente, das autoridades governamentais, no sentido de estabelecer estratégias que maximizem e otimizem a utilização dos recursos públicos. Em Goiás, com uma população de 7.018 .354 pessoas (IBGE, 2019), os cenários, acompanhando o desenho na escala nacional e internacional, motivam preocupação diária.

O debate entre aqueles que pretendem priorizar a economia em detrimento da saúde supõe um falso dilema, uma vez que equipara o valor universal da vida aos valores monetários. Isso não merece crédito em sociedades democráticas. Porém, não estamos desconsiderando os desafios econômicos, pois em uma economia de base monetária, emprego e renda são fundamentais na reprodução da vida das famílias, afetando, diretamente, a alimentação, a moradia e, portanto, a saúde. 
4 A urgência da ocasião demanda a construção de estratégias políticas e econômicas para garantir a renda mínima, primeiro, para a parcela da população mais vulnerável e, segundo, para a parcela que, em função da crise, encontra-se, temporariamente, sem renda originária do trabalho formal e/ou informal. o debate moral sobre a origem da renda advinda do trabalho, pressuposto da natureza empreendedora, e a renda compensatória, derivada de programas de transferência de renda, perde, momentaneamente, sua centralidade política. ${ }^{1}$

Figura 1. Esquema simplificado de proposta de hierarquização institucional das transferências de renda direta e indireta

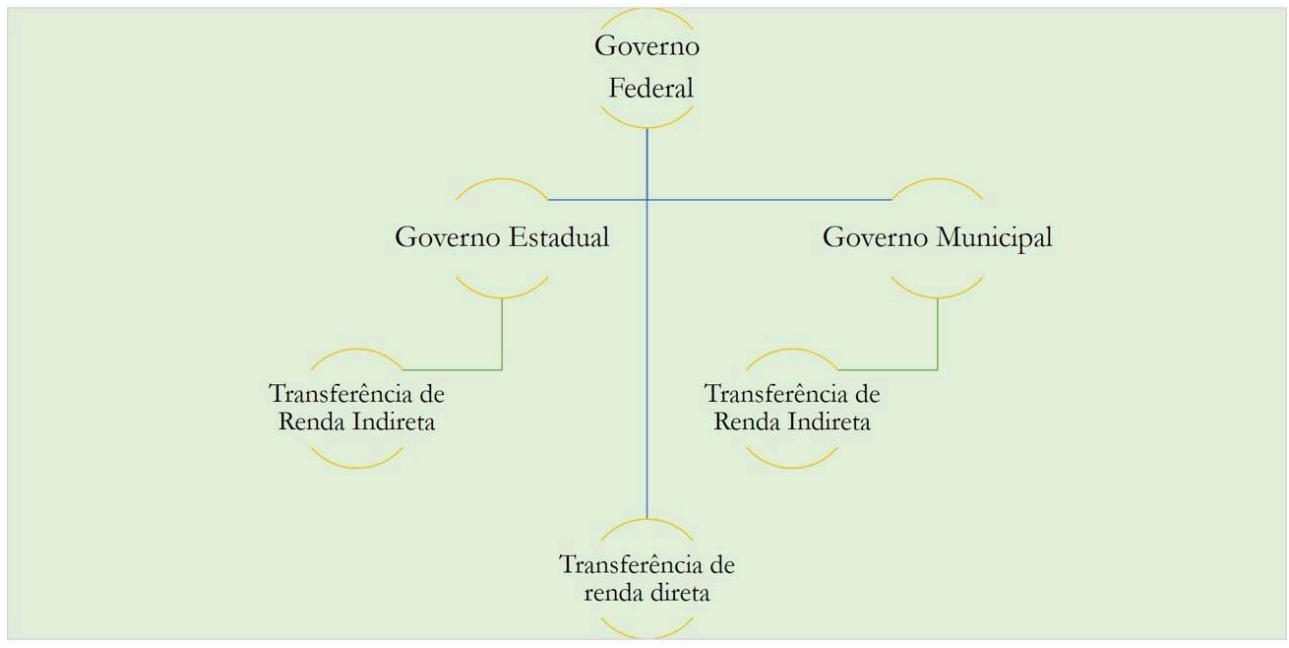

Fonte: dos autores

Conforme sintetizado na Figura 1, tradicionalmente, existem duas formas de transferência de renda²: i) a transferência de renda direta monetária, com ou sem condicionalidades; ii) a transferência de renda indireta, resultado da oferta de serviços públicos como saúde e educação ou mesmo de programas emergenciais de auxílio aos mais vulneráveis. As duas transferências de renda podem partir de princípios focalizadores, do ponto de vista dos grupos sociais, ou de princípios universais, atendendo, sem distinção, todos os cidadãos. Essas transferências, destinadas ao conjunto da população mais vulnerável, deve, em momentos de crise, apresentar-se como uma solução conjuntural de baixa complexidade burocrática. A eficácia de ações desse gênero, no contexto federativo brasileiro e com a urgência que deriva, exigirá um esforço inédito de articulação institucional.

O protagonismo do Governo Federal nas ações de transferência de renda monetária deveria ser proporcional à centralização dos recursos monetários nessa escala. Em que pese os esforços de descentralização impulsionados a partir da Constituição Federal de 1988, os recursos continuam centralizados na esfera federal. Do modo inverso, especialmente nos municípios pouco populosos, que dependem de transferências constitucionais do Governo Federal e do Governo Estadual, os governos municipais não dispõem de recursos monetários para implementação de programas de transferência de renda. A transferência de renda ocorre, nessa escala, basicamente, a partir do emprego público municipal (ARRAIS, 2019). É também nessa escala que se sedimenta a amálgama necessária para operacionalização das políticas assistenciais, a exemplo do desenho institucional dos CRAS (Centro de Referência de Assistência Social) e do CREAS (Centro 
de Referência Especializado de Assistência Social). No Brasil, segundo dados do Censo SUAS 2018 (MDS, 2018), havia 8.370 CRAS e 2.717 CREAS, o que dá a exata noção da capilaridade da rede de assistência social nacional.

7 Neste artigo é destacada a necessidade de uma ação conjunta e articulada entre os entes federados (União, Estados e Municípios) para superar os desafios da crise generalizada que atinge, de diferentes modos, a totalidade da população brasileira. As políticas de transferência de renda (direta e indireta) são instrumentos eficazes, se focados nos grupos e espaços mais vulneráveis, e com a agilidade necessária, para amortecer os efeitos da crise.

\section{Particularidades do desenvolvimento regional goiano}

8 Existem particularidades no território goiano que devem ser consideradas quando analisamos estratégias de ação, do ponto de vista da implementação de políticas de transferência de renda, para amenizar os efeitos econômicos da pandemia, dentre as quais, destacamos:

9 A rede urbana goiana, formada, predominantemente por municípios abaixo de $20 \mathrm{mil}$ habitantes (Figura 2) deve ser considerada como fator positivo nas estratégias de minimização dos danos econômicos da pandemia. Dos 246 municípios goianos, 187 têm população inferior a 20 mil habitantes. $\mathrm{O}$ core da urbanização goiana corresponde ao eixo da BR-060, compreendendo os municípios do Sudoeste Goiano, da Região Metropolitana de Goiânia (RMG), incluindo Anápolis e do Entorno do Distrito Federal. Nessa região encontram-se, ao mesmo tempo, os municípios mais populosos e povoados, assim com as áreas específicas, considerando a análise intraurbana, com maiores demandas de infraestrutura, fundamentalmente saneamento básico. 
Figura 2. Tipologia por classe populacional dos municípios goianos, 2019

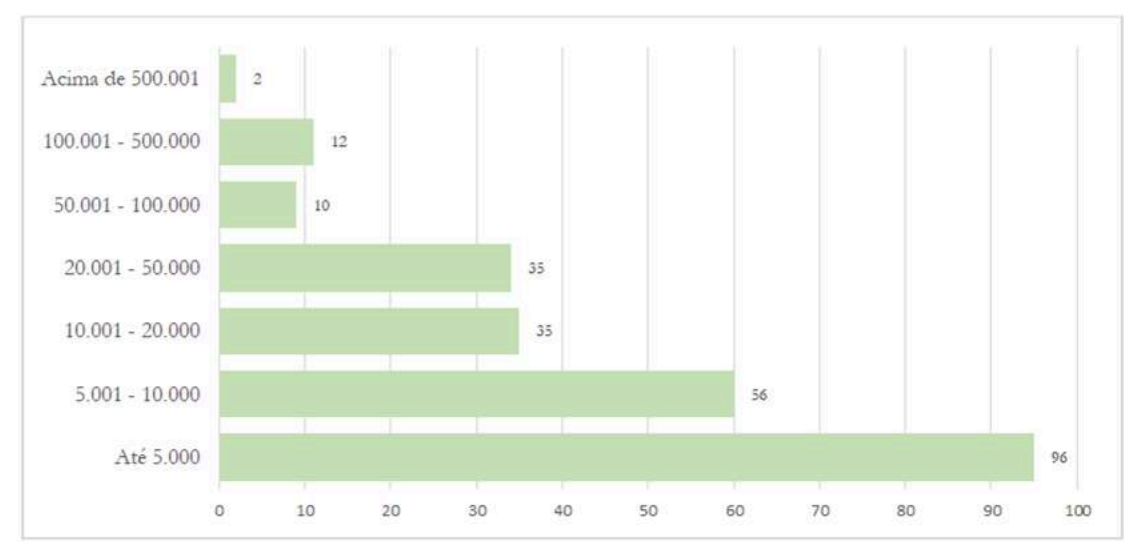

Fonte: IBGE (2019)

O perfil produtivo regional reverbera, ao mesmo tempo, na oferta desigual dos empregos formais e informais no território goiano, bem como na produção agrícola e pecuária. Esse perfil deve ser observado, no momento atual, a partir da oferta de bens de consumo não duráveis, mas também pelo potencial na manutenção e geração de novos empregos. Esse é um ponto positivo que pode ser explorado. A produção agrícola e pecuária, associada à indústria alimentícia, garante a circulação regional de mercadorias e os excedentes para exportação. É oportuno lembrar que essas áreas apresentam densidades demográficas e de empregos (comércio e serviços) distintas das duas áreas metropolitanas (Região Metropolitana de Goiânia e Entorno do Distrito Federal), fato positivo quando consideramos, primeiro, a área de expansão $\mathrm{e}$ concentração das demandas e, segundo, as áreas que serão mais afetadas pela pandemia. Dos 1.507.648 empregos formais registrados em Goiás, em 2018, 31\% foram gerados no setor de serviços e 19,5\% no setor de comércio (MTE-RAIS, 2018). Um ponto positivo, nesse momento, é que o setor da administração pública respondeu por $22 \%$ do emprego formal, sendo, também, o único setor com predomínio da presença de mulheres no estado de Goiás. Assim, é fácil perceber que o maior impacto, do ponto de vista da renda e emprego formal privado, considerando os setores descritos na Figura 3, será no comércio e nos serviços que se concentram na área core da urbanização goiana.

Espaço e Economia, 18 | 2020 
Figura 3. Goiás, número de empregos formais por setor e gênero, em 31 de dezembro de 2018

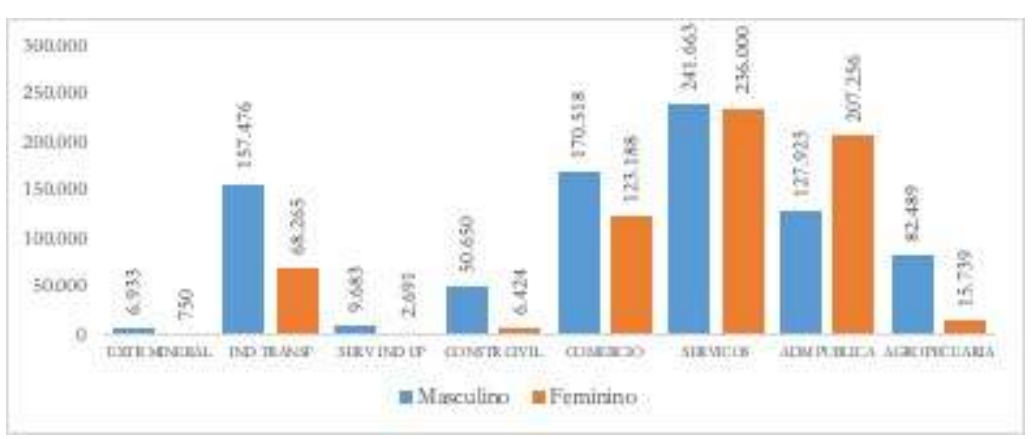

Fonte: MTE-RAIS (2018)

O perfil demográfico da população guarda estreita relação com a renda, bastando para isso verificar que a elevação da desocupação, no Brasil, atinge, com mais intensidade, as pessoas entre 14 e 29 anos de idade. A desocupação, nesse grupo, passou de $13 \%$ em 2014 para 22,6\% em 2017 (IBGE, 2018). Portanto, se a preocupação, do ponto de vista médico-sanitário, é focada nos idosos, do ponto de vista econômico, deve ser vertida para a população em idade ativa. A população em Goiás, acima de 60 anos, segundo projeções para o ano de 2020 , equivale a 850.220 pessoas, o que corresponde a $12,11 \%$ da população total (IMB, 2018). A análise desse perfil, necessário para focalização de programas de transferências de renda, é distinta regionalmente, como indica a Figura 4. Essa população, especialmente nos municípios abaixo de 20.000 habitantes, encontra-se contemplada, muito embora ainda abaixo do ideal, por razões burocráticas, pelos benefícios da Aposentadoria Rural e os benefícios de Prestação Continuada.

Figura 4. População total e acima de 60 anos, projetada para 2020, municípios selecionados

\begin{tabular}{|c|c|c|c|c|c|c|}
\hline \multirow{2}{*}{ Município } & \multirow{2}{*}{$\begin{array}{l}\text { População } \\
\text { total }\end{array}$} & \multicolumn{3}{|c|}{$\begin{array}{l}\text { Total população projetada acima } \\
\text { de } 60 \text { anos }\end{array}$} & \multirow{2}{*}{$\begin{array}{lr}\text { Percentual } & \text { em } \\
\text { relação } & \text { ao } \\
\text { município } & \end{array}$} & \multirow{2}{*}{ Localização } \\
\hline & & Feminino & Masculino & Total & & \\
\hline $\begin{array}{l}\text { Águas Lindas } \\
\text { de Goiás }\end{array}$ & 207.465 & 5.554 & 5.715 & 11.269 & 5,5 & $\begin{array}{l}\text { Entorno do } \\
\text { DF }\end{array}$ \\
\hline $\begin{array}{l}\text { Aparecida de } \\
\text { Goiânia }\end{array}$ & 589.330 & 19.983 & 25.741 & 45.724 & 7,8 & RMG \\
\hline Goiânia & 1.516 .662 & 116.578 & 82.249 & 184.037 & 13,1 & RMG \\
\hline Pilar de Goiás & 2.438 & 223 & 264 & 487 & 19,9 & $\begin{array}{l}\text { Centro } \\
\text { Goiano }\end{array}$ \\
\hline
\end{tabular}

\section{Fonte: IMB (2018)}

12 As três particularidades, necessariamente, não precisam guardar correlação com a ocorrência de casos e/ou mesmo óbitos resultantes do Coronavírus. No entanto, as ações sociais de transferência de renda direta e indireta que ocorrerão no conjunto dos municípios do estado precisam, prioritariamente, considerar os contextos regionais econômicos, especialmente o estoque de empregos formais e a dimensão do mercado 
informal, e os contextos regionais demográficos, especialmente a estrutura etária. Necessariamente, como veremos, o fato de municípios de menor peso demográfico concentrarem proporcionalmente o maior número de idosos, pode não significar que terão mais demandas de renda, uma vez que a cobertura da Aposentadoria Rural ou do Benefício de Prestação Continuada, além da massa salarial proporcional da administração pública, podem suprir as necessidades básicas de reprodução da vida.

Figura 5. Esquematização simplificada das transferências de renda direta e indireta

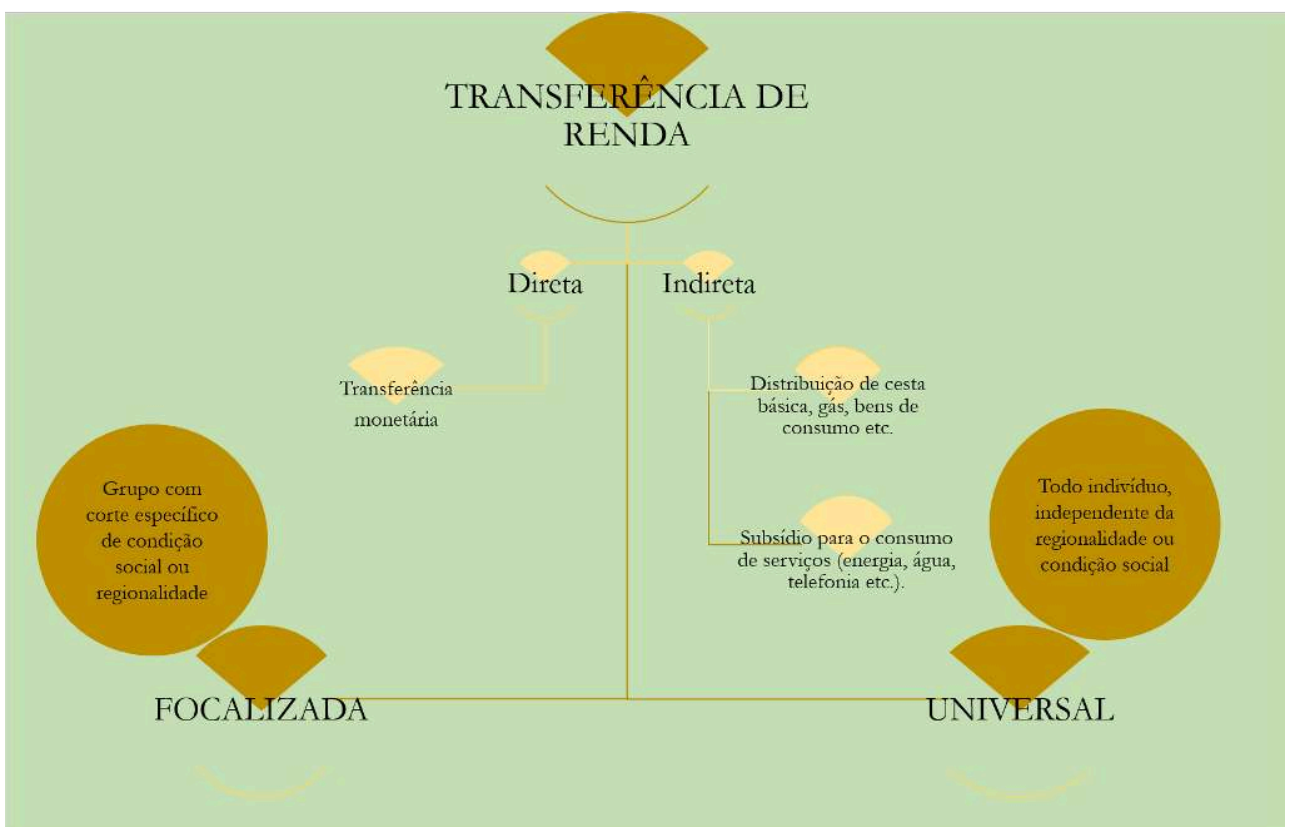

Fonte: dos autores

13 A crise exigirá ações no campo da economia e da assistência social que, mesmo secundárias, quando consideramos os investimentos na infraestrutura médicohospitalar, devem ser objeto de atenção. Manter o fluxo de renda ou amenizar a redução da renda em circulação é um esforço que acarreta, em curto prazo, efeitos sistêmicos. O beneficiário da renda é, também, um consumidor do varejo que move a economia dos pequenos núcleos urbanos, assim como das periferias urbanas. $O$ efeito imediato das transferências direta e indireta de renda é percebido no consumo de alimentos, de produtos de higiene e limpeza, medicamentos, ou seja, de bens de consumo não duráveis com forte organicidade com a cadeia produtiva regional e nacional. Ainda na linha dos efeitos econômicos das transferências de renda monetária, estudo de Neri et al. (2013), vinculado ao IPEA, sobre o Bolsa Família, aponta que, a cada $\mathrm{R} \$ 1$ gasto, $\mathrm{R} \$ 1,78$ é incorporado ao PIB (Produto Interno Bruto). Esse argumento nos autoriza a imaginar que, diferente do gasto com pagamento de juros e ou rendimentos de aplicações financeiras complexas, as transferências de renda, além de funcionais para o mercado urbano, reduzem as desigualdades sociais. 


\section{Exercício de espacialização do fluxo de renda individual}

14 Há muitas formas de se analisar o desempenho econômico municipal. A mais comum é a comparação do PIB ou mesmo dos valores adicionados do PIB, perspectivas que permitem entender a relevância de determinadas atividades econômicas na escala municipal. No entanto, em razão de sua natureza abstrata, as medidas do PIB não são suficientes para a compreensão do fluxo de renda, sendo mais úteis as informações sobre as fontes e o volume dos rendimentos individuais. Por fluxo de renda individual compreendemos os valores monetários destinados de forma regular aos indivíduos, resultado de rendas do trabalho, das aposentadorias e das pensões, além das transferências de renda direta do poder público. Esse quadro não inclui aquilo que Piketty (2014) definiu como "renda de atividades não assalariadas", a exemplo dos aluguéis, dos rendimentos de aplicações financeiras ou repartição de dividendos de empresas. Em Goiás, os três subgrupos, apresentados na Figura 6, compostos por empregos formais, transferências de renda direta e benefícios previdenciários, totalizaram 2.933.933 fontes de renda. ${ }^{3}$

Figura 6. Esquema simplificado de fluxo de renda em Goiás.

\begin{tabular}{|c|c|c|c|c|c|}
\hline $\begin{array}{l}\text { Fonte do } \\
\text { rendimento }\end{array}$ & Discriminação & $\begin{array}{l}\text { Total } \\
\text { formais, } \\
\text { beneficiadas } \\
\text { benefícios in }\end{array}$ & $\begin{array}{r}\text { vínculos } \\
\text { famílias } \\
\text { e } \\
\text { dividuais }\end{array}$ & 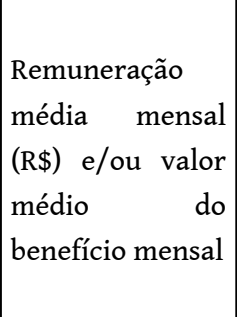 & $\begin{array}{l}\text { Massa de rendimento } \\
\text { anual bruta } \\
\text { proveniente do } \\
\text { trabalho formal, das } \\
\text { transferências e } \\
\text { benefícios } \\
\text { previdenciários* }\end{array}$ \\
\hline Emprego (2018) & Formal & 1.507 .648 & & $2.561,73$ & $46.346 .234 .583,00$ \\
\hline \multirow{4}{*}{$\begin{array}{l}\text { Transferência } \\
\text { de Renda } \\
\text { Direta (2019) }\end{array}$} & Bolsa Família & \multicolumn{2}{|l|}{277.003} & 168,81 & $561.117 .247,00$ \\
\hline & \multirow{2}{*}{ BPC } & Idosos & 70.865 & 993,71 & $845.030 .503,68$ \\
\hline & & Deficientes & 84.730 & $1.004,63$ & 1.021.468.613,15 \\
\hline & $\begin{array}{l}\text { Aposentadoria } \\
\text { Rural }\end{array}$ & 291.063 & & 978,52 & 3.417.738.914,54 \\
\hline \multirow{2}{*}{$\begin{array}{l}\text { Benefícios } \\
\text { Previdenciários } \\
\text { (2019) }\end{array}$} & Aposentadorias & \multicolumn{2}{|l|}{485.655} & $1.313,82$ & 7.656.735.886,15 \\
\hline & Pensões & \multicolumn{2}{|l|}{216.969} & $1.183,00$ & $3.080 .092 .756,74$ \\
\hline
\end{tabular}

Fontes: RAIS/MTPS (2018), MDS (2019), INSS (2019).

*Para obter a massa estimada de renda (R\$) multiplicamos os valores mensais por 12.

15 Do total das fontes de renda discriminadas, a mais sensível à conjuntura da crise é o emprego formal. Em 2018, do total da massa de rendimento anual estimado para todos os municípios do estado de Goiás, 34,5\% concentrou-se na administração pública, 28,6\% 
nos serviços e $13,5 \%$ no comércio. A preocupação preliminar com a variação do emprego formal justifica-se pelo fato de concentrar 50,0\% dos vínculos de renda e 72,9\% da massa de rendimento anual estimada para o estado de Goiás no ano de 2018. Contudo, as transferências de renda direta e as aposentadorias e pensões do INSS (Instituto Nacional de Seguridade Social), em 2019, responderam por 27,1\% do fluxo de renda indicado, focando, certamente, uma parte da população mais vulnerável, do ponto de vista da renda, do território goiano.

Figura 7. Percentual de massa de rendimento anual estimado, vínculos selecionados, 2018
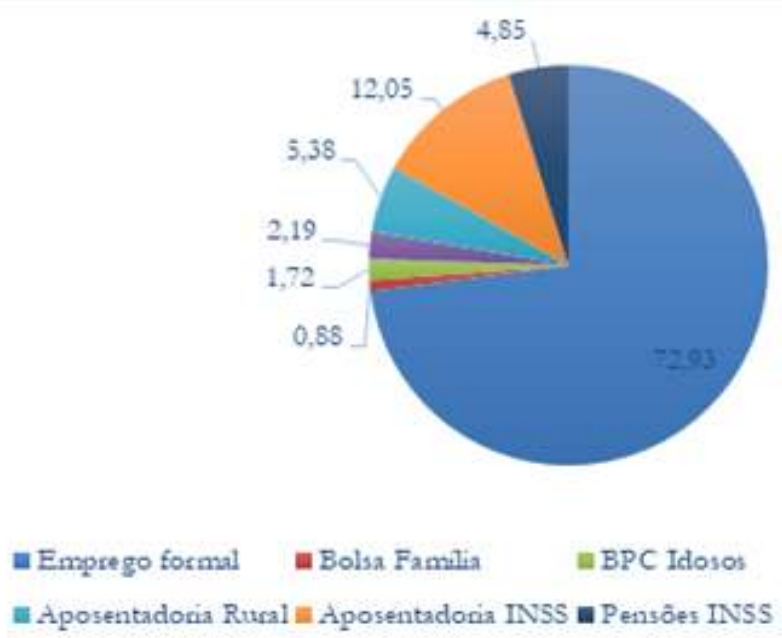

- BPC Deficientes

Fonte: INSS (2019), RAIS-MTE (2018), MDS (2019)

16 A análise dos cartogramas por segmento revela padrões de distribuição e concentração de renda que podem, grosso modo, auxiliar na construção de políticas de transferência de renda direta e indireta. Não podemos perder de vista que a ausência e/ou redução brusca de renda é um fator decisivo no aumento da vulnerabilidade social dos indivíduos. A espacialização do fluxo de renda permite compreender, em escalas regionais, aqueles municípios que serão mais atingidos, por exemplo, por problemas relacionados ao desemprego e/ou perda de renda monetária.

\section{Perfil regional da renda do emprego formal}

17 Há, inegavelmente, um perfil regional do emprego formal que se diferencia em relação ao total de vínculos, ao volume de renda gerada e a participação dos setores na geração total de empregos (Figuras 8, 9 e 10). O mais importante, nessa análise, é a relação entre o total de empregos na escala municipal e a participação relativa, também na escala municipal, na oferta total de empregos formais. Em 18 dos 246 municípios goianos, a massa salarial da administração pública esteve entre $70,7 \%$ e $89,6 \%$ do total da massa salarial municipal; e em outros 64 municípios esse percentual localizou-se entre 50,0\% e 69,8\%. Em 79 municípios, a participação da massa salarial da administração pública localizou-se entre $30,01 \%$ e $49,5 \%$. A maior parte desses municípios localizam-se no Nordeste Goiano, no Norte Goiano, no Noroeste e no Centro Goiano. 
Figura 8. Goiás, total de vínculos empregatícios formais, por município, dezembro de 2018

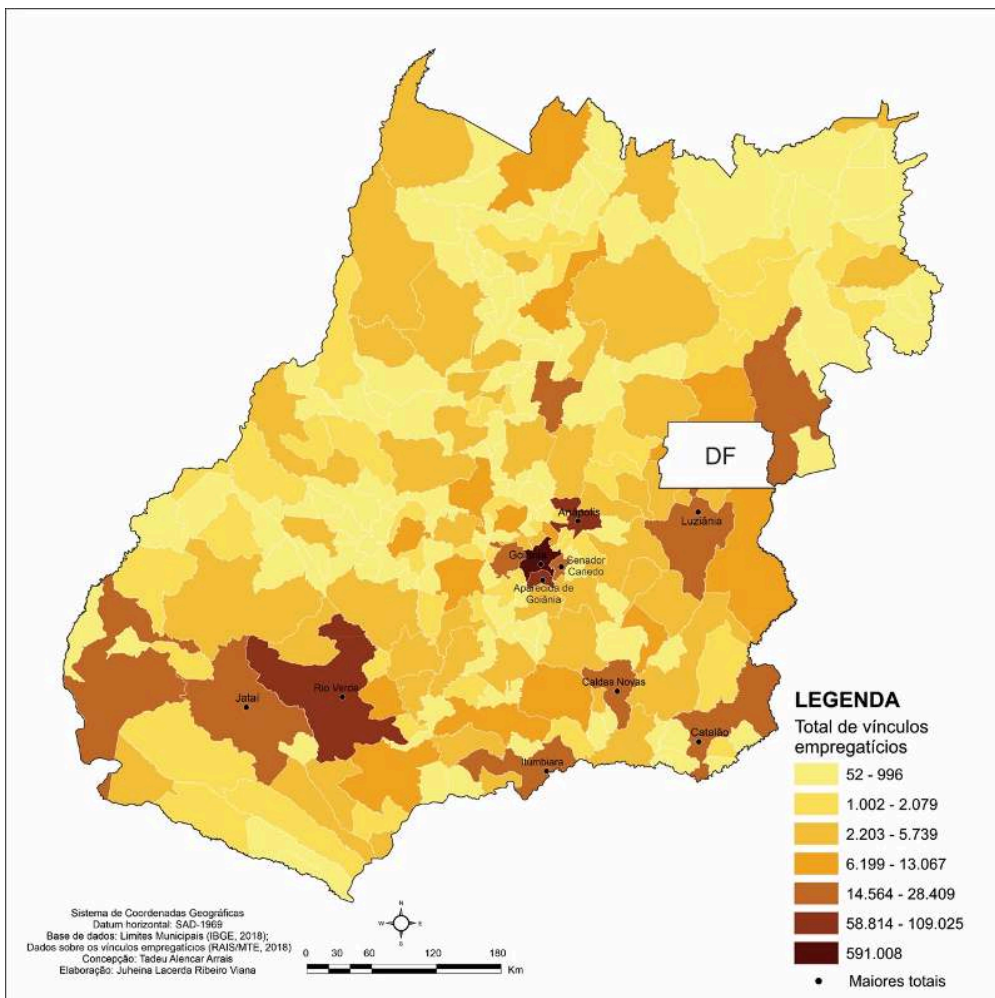

Fonte: RAIS-MTE (2019)

Figura 9. Goiás, remuneração média (R\$) dos empregos formais, por município, dezembro de 2018

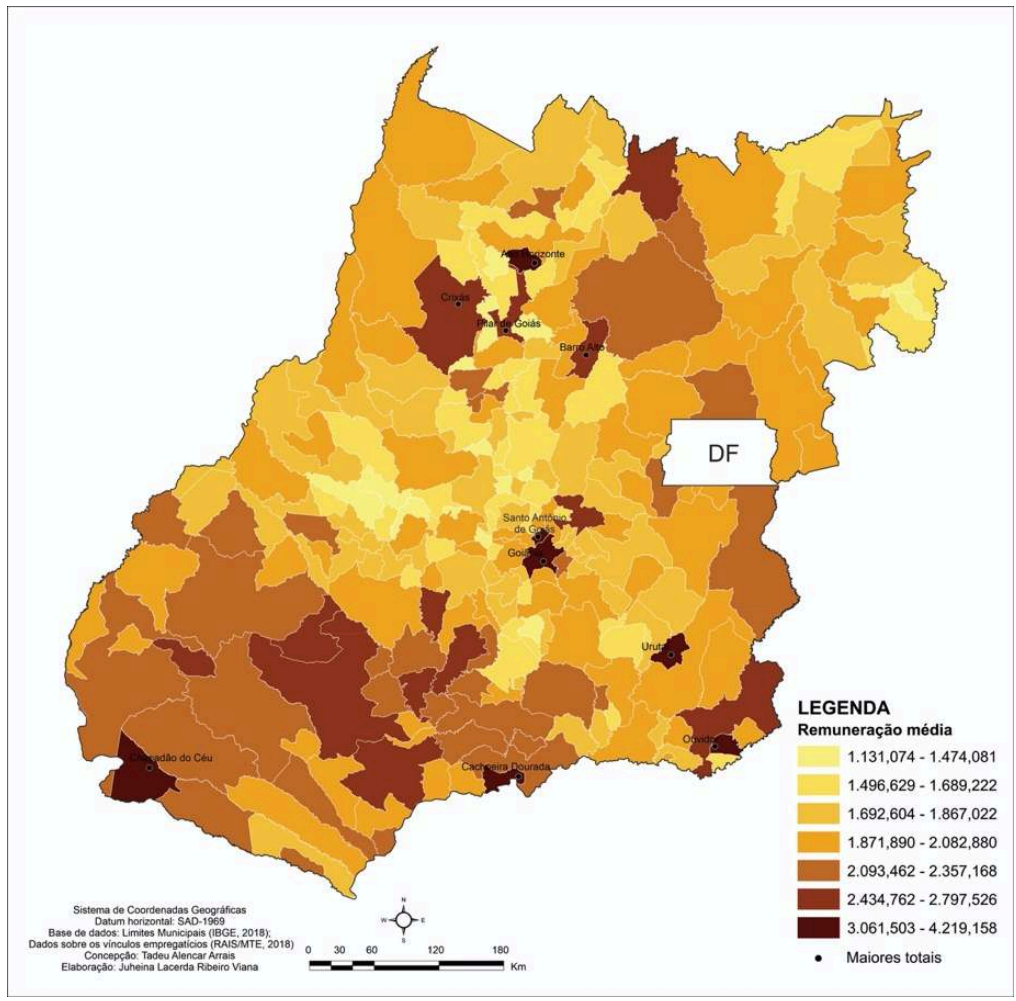

Fonte: RAIS-MTE (2019) 
Figura 10. Goiás, percentual de vínculos empregatícios dos setores formais, dezembro de 2018

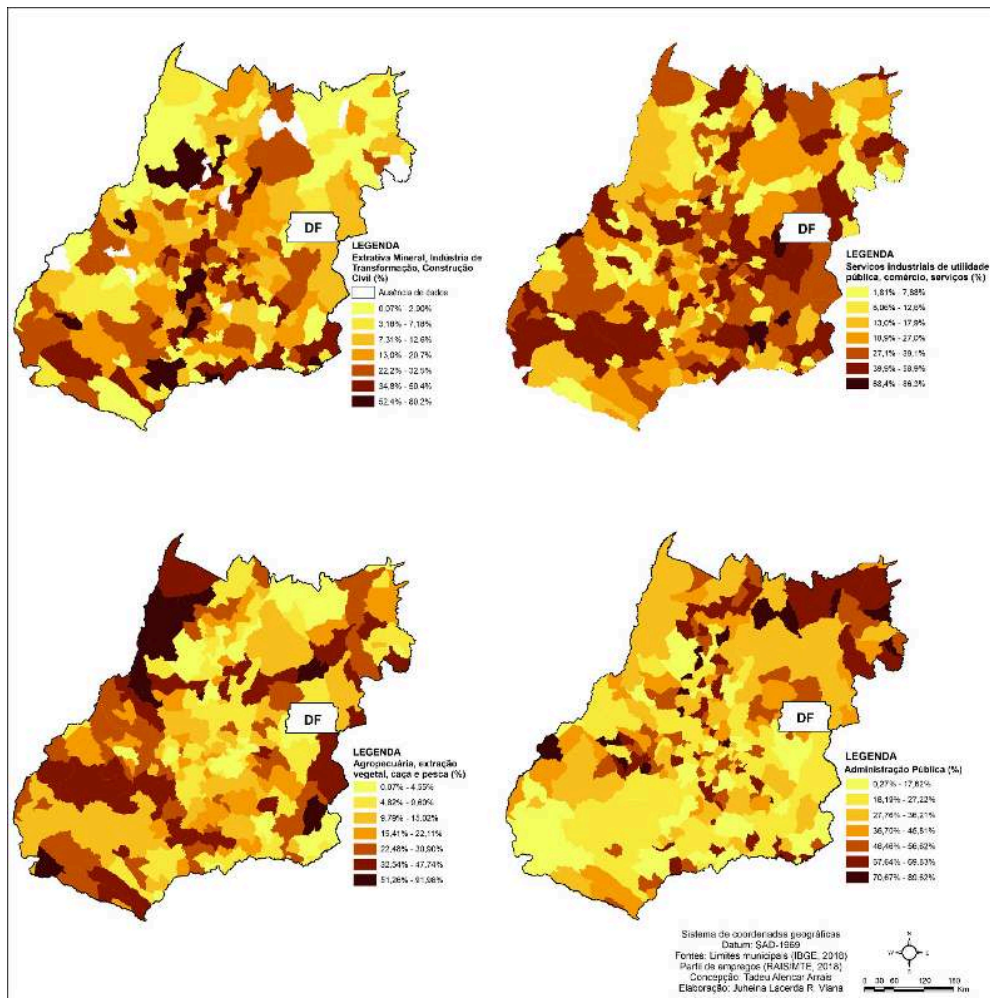

Fonte: RAIS-MTE (2019)

Figura 11. Goiás, massa salarial média estimada dos empregos formais, dezembro de2018

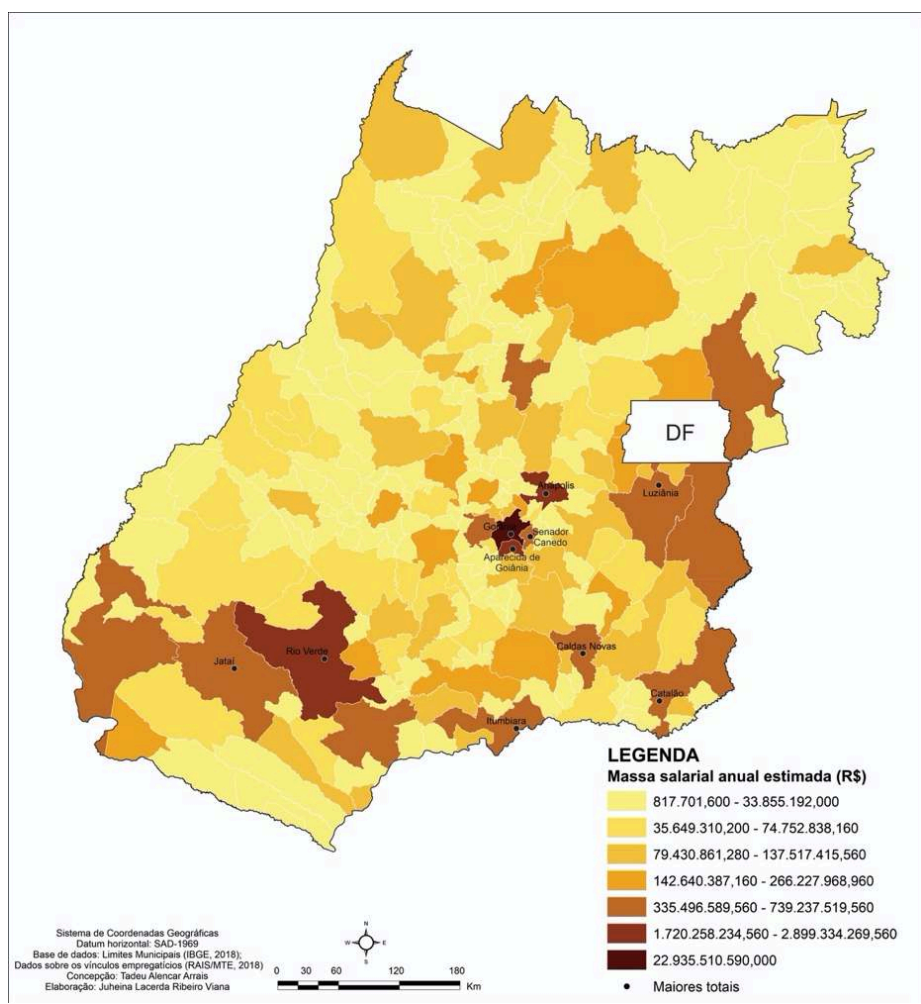

Fonte: RAIS-MTE (2019) 
Figura 12. Goiás, total de vínculos empregatícios por município, por faixa de Salário Mínimo, dezembro de 2018.

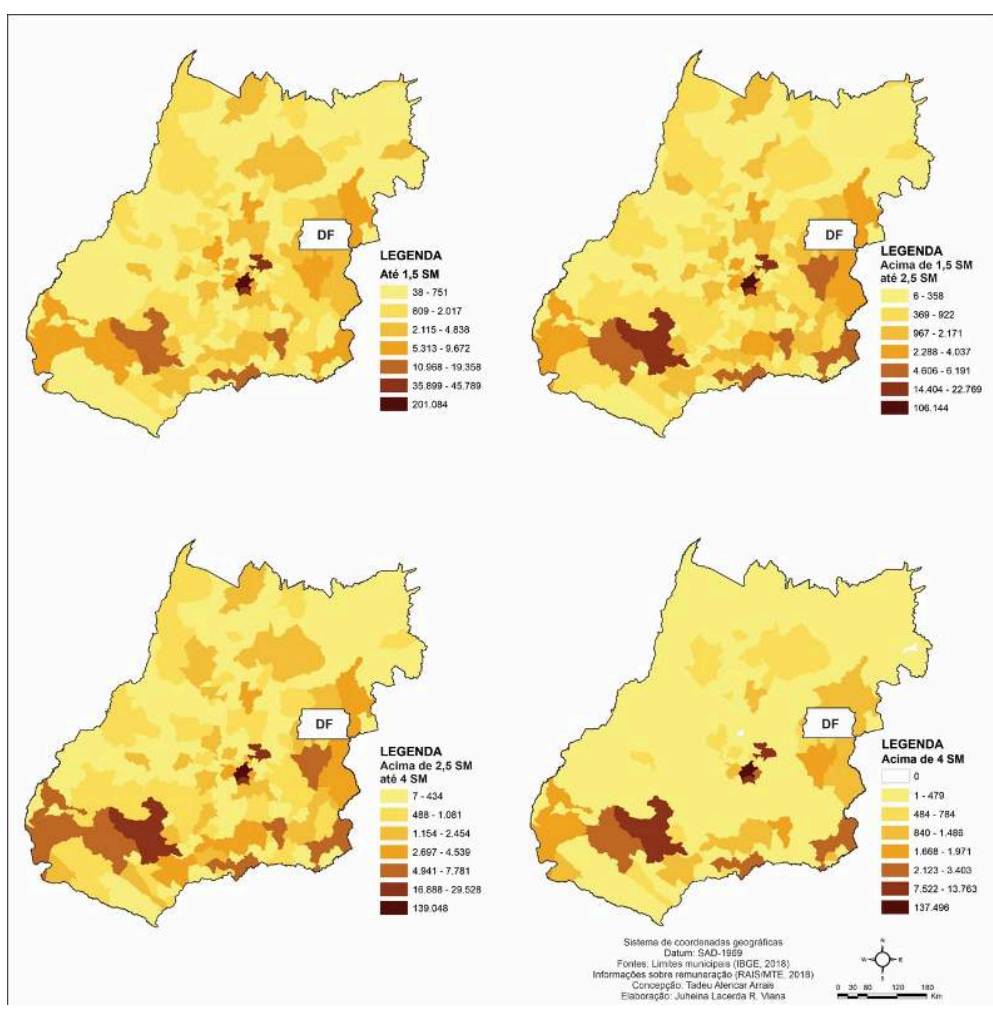

Fonte: RAIS-MTE (2019)

Figura 13. Goiás, municípios com maior participação do setor da administração pública no emprego formal, dezembro de 2018

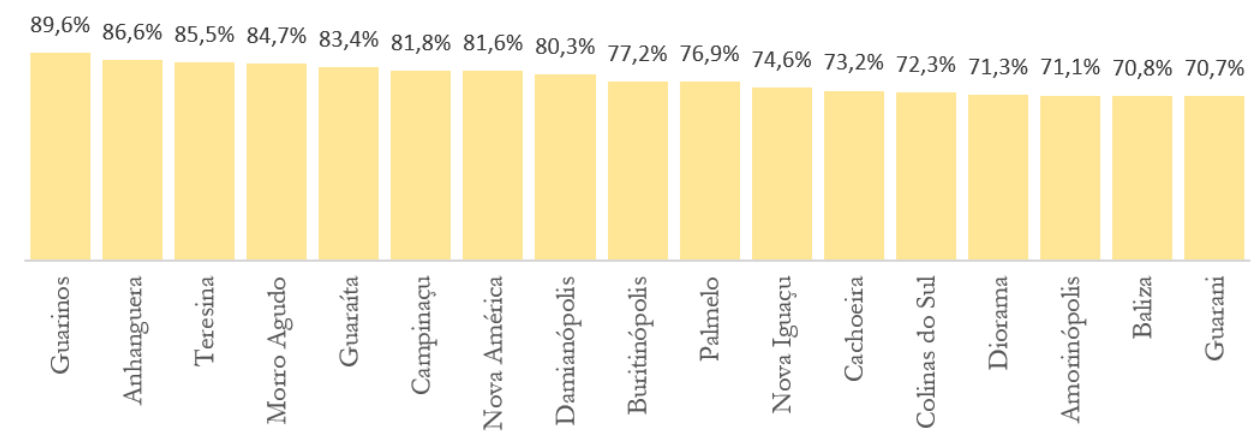

Fonte: RAIS-MTE (2019)

Os municípios com menor participação da administração pública, do ponto de vista relativo, na geração de empregos formais localizam-se no core da urbanização goiana, equivalente ao eixo da BR-060, mas também se encontram pulverizados no sudeste e sudoeste goiano. Também nessas regiões estão concentradas as maiores remunerações médias. A renda média do município de Ouvidor $(\mathrm{R} \$ 4.219,16)$ é 3,7 vezes maior que a renda média do município de Buriti de Goiás (R\$1.131,07).

Entretanto, existem diferenças substanciais quando comparamos os setores. $O$ setor de Serviço Industrial de Utilidade Pública $(\mathrm{R} \$ 5.666,00)$ é aquele de maior renda e o de 
serviços ( $\mathrm{R} \$ 1.777,00)$, o de menor renda, dado fundamental para pensar políticas de transferência de renda local, já que esse setor, de maior concentração de empregos, absorveu, em 2018, 477.663 pessoas.

Antes de assumir, a priori, o discurso negativo sobre a participação da administração pública na geração de empregos formais, é oportuno considerar que a realização das suas funções constitucionais do Estado, especialmente na saúde, educação e segurança pública, demanda a presença de uma estrutura técnico-burocrática que se territorializa nos municípios de forma diferenciada. A expansão do emprego público está, portanto, estreitamente ligada à ampliação das funções do Estado nas escalas federal, estadual e municipal. Ocorre que o vínculo formal das três escalas, devido a dinâmica de concentração dos serviços públicos, é diferencial, bastando para isso observar que Goiânia concentra um volume expressivo de funcionários públicos federais e estaduais.

O importante na discussão, no entanto, é entender que a política de transferência de renda monetária deve considerar o perfil regional do emprego, atentando-se para: 1) a preservação do emprego formal público, especialmente nos municípios de menor peso demográfico, que garante a renda; 2) construir meios de financiamento da produção para garantir os empregos formais, especialmente no eixo de urbanização, concentrador da economia de serviços, ao mesmo tempo em que, também, na região core da urbanização, implementar políticas de transferência focalizadas naqueles indivíduos que dependem da renda do mercado informal.

\section{Perfil regional da renda das transferências diretas}

As Figuras 14 e 15 oferecem um retrato do programa de transferência de renda de maior capilaridade no território brasileiro. Aproveitar a expertise burocrática desenvolvida no processo de construção do programa Bolsa Família é fundamental nesse momento. $O$ programa focaliza famílias em situação de pobreza (renda per capita entre $R \$ 85,01$ a $R \$ 170,00$ ) e extrema pobreza (renda per capita até $R \$ 85,00$ ).

Figura 14. Síntese dos marcos institucionais dos programas de transferência de renda direta

\begin{tabular}{|l|l|l|r|}
\hline Tipo de benefício & Origem & Público alto & $\begin{array}{l}\text { Beneficiários } \\
2019-\text { Goiás }\end{array}$ \\
\hline $\begin{array}{l}\text { Aposentadoria } \\
\text { Rural }\end{array}$ & $\begin{array}{l}\text { LC n } \text {. 11, de 1971, instituiu o Programa } \\
\text { de Assistência ao Trabalhador Rural, } \\
\text { com idade de 65 anos e 50\% do Salário } \\
\text { Mínimo destinado ao chefe de família. }\end{array}$ & $\begin{array}{l}60 \text { anos para homens e 55 anos para } \\
\text { mulheres, com 1 Salário Mínimo. }\end{array}$ & 291.063 \\
\hline $\begin{array}{l}\text { Benefício de } \\
\text { Prestação } \\
\text { Continuada }\end{array}$ & $\begin{array}{l}\text { Lei n. 6.179 (1974), que instituiu o } \\
\text { Amparo Previdenciário. Lei n. 8.742 de } \\
1993 .\end{array}$ & $\begin{array}{l}\text { 1 Salário Mínimo para pessoas com } \\
\text { deficiência e idosos pobres, com renda } \\
\text { per capita até 1/4 do SM acima de 65 } \\
\text { anos. }\end{array}$ & 155.595 \\
\hline Bolsa Família & $\begin{array}{l}\text { MP 132 de 2003 e Lei número 10.836, } \\
\text { em 2004. }\end{array}$ & $\begin{array}{l}\text { Famílias em situação de pobreza (renda } \\
\text { per capita entre R\$ 85,01 a R\$ 170,00) } \\
\text { e extrema pobreza (renda per capita até } \\
\text { R\$ 85,00) }\end{array}$ & 277.003 \\
\hline
\end{tabular}

Fonte: Brasil (1971, 1974 e 2003), INSS (2017), MDS (2017) 
Figura 15. Goiás, total e valor dos benefícios do Bolsa Família e cobertura do Cadastro Único, por município, 2019

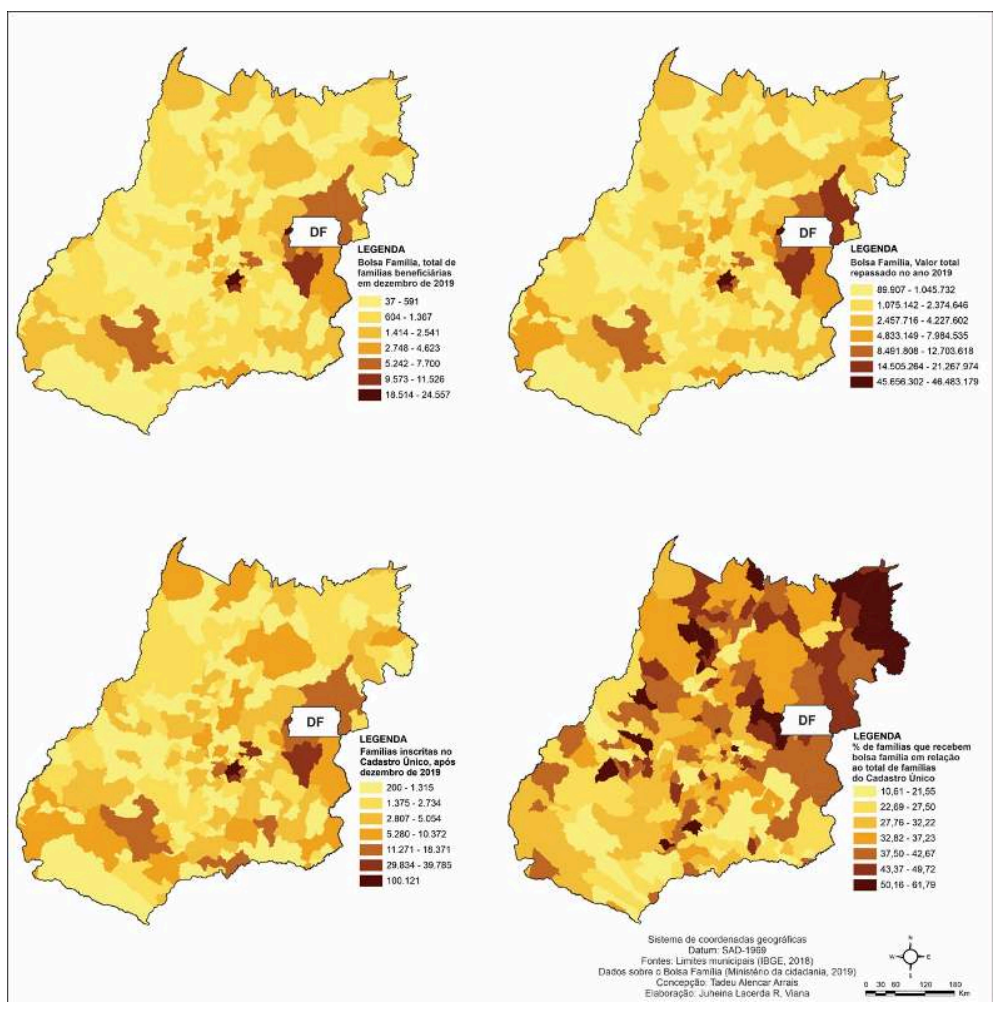

Fonte: MDS (2019)

O Cadastro Único para Programas Sociais é a porta de entrada para o Bolsa Família. Em Goiás, em 2019, 837.302 famílias encontravam-se inscritas nesse cadastro. Do ponto de vista do total de benefícios do Bolsa Família, assim como do valor, identificamos uma concentração em municípios como Águas Lindas de Goiás, Luziânia, Goiânia, Aparecida de Goiânia, Senador Canedo, indicando um perfil urbano, acompanhando o padrão brasileiro. Trata-se de um programa, em termos de custos, barato, especialmente quando consideramos as condicionalidades, como indicado por Alencar (2020). Os 10 municípios goianos com maior volume de benefícios totalizaram 108.261 famílias beneficiadas, ao custo total de $\mathrm{R} \$ 214.775 .430,00$. A análise da Figura 15, no entanto, indica também as áreas de baixa cobertura, como o Nordeste e Norte Goiano. Mas por que isso ocorre, especialmente quando consideramos que essas regiões são consideradas as menos "desenvolvidas" do estado de Goiás?

A resposta para a interrogação está na análise de outros dois programas de transferência de renda evidenciados, como será apresentado na Figura 17. Trata-se da Aposentadoria Rural e do Benefício de Prestação continuada. Em 2019 foram destinados para beneficiários dos dois programas 446.658 benefícios, no valor individual de 01 Salário Mínimo. Isso fez toda diferença e explica o incremento na renda familiar nos municípios pouco densos e com perfil agrícola. Os 10 municípios com maior número de beneficiários da Aposentadoria Rural concentraram 66.607 benefícios, somando R\$ 778.810.778,00.

Os benefícios da Aposentadoria Rural guardam a particularidade de impactar no campo, via custeio e pequenos investimentos para a manutenção de atividades agropecuárias, mas também na manutenção da vida de idosos na cidade onde se tornaram, em muitos 
casos, verdadeiros arrimos de família. A mancha vermelha do mapa não deixa dúvidas da importância diferencial com relação às regiões goianas e, por consequência, o maior e/ou menor grau de relevância dos recursos dos benefícios rurais para as economias municipais.

A questão é simples - quanto mais aposentados rurais, maior será o fluxo de renda para o município. A maior renda, especialmente no corte etário de destinação, implica em redução da vulnerabilidade social na terceira idade, aumento da circulação de renda no varejo municipal e, principalmente, o custeio e pequenos investimentos nas propriedades rurais.

Figura 16. Municípios goianos com maior volume BPC, portador de deficiência, 2019

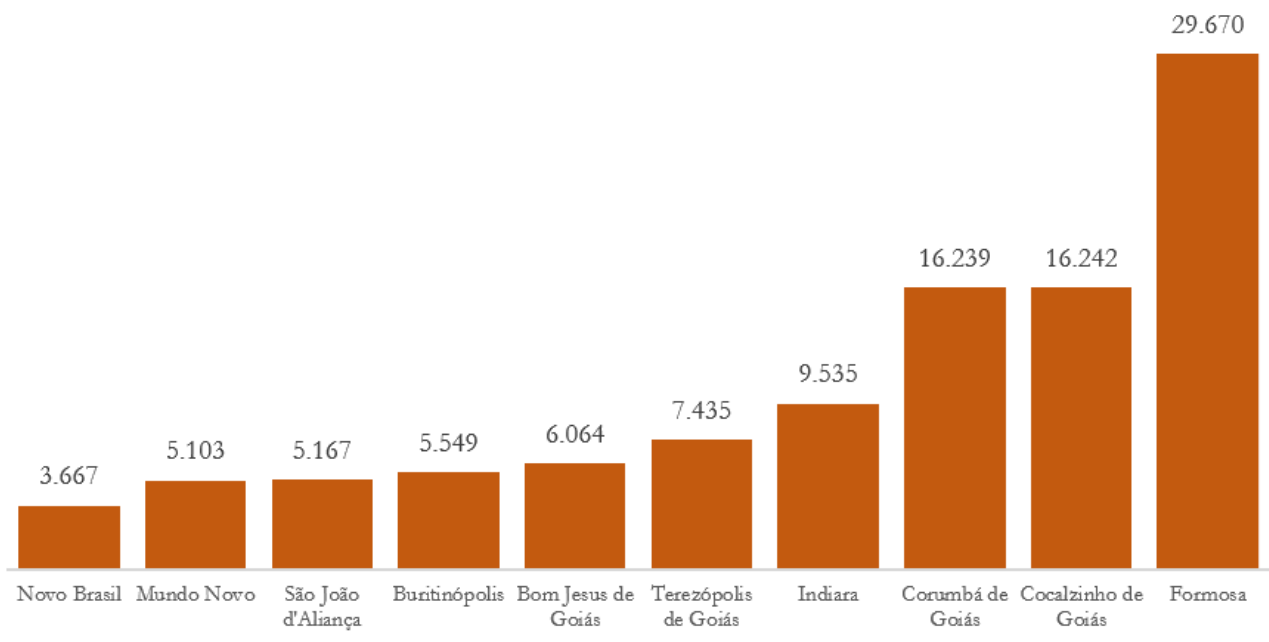

Fonte: INSS (2019)

Se por um lado a Aposentadoria Rural garante benefícios para trabalhadores com vínculo rural, o Benefício de Prestação Continuada atende idosos pobres e deficientes com o suprimento de um Salário Mínimo mensal (Figuras 17 e 18). Para idosos pobres foram destinados $\mathrm{R} \$ 845.030 .503,68$, equivalentes a 70.865 beneficiários e, para deficientes pobres, $\mathrm{R} \$ 1.021 .468 .613,15$, equivalente a 84.730 benefícios. Em 10 municípios goianos, como descrito na Figura 16, há registros da presença de mais de 2.047 beneficiários na modalidade deficiente. Esse programa, considerando o universo de beneficiários, contempla a parte mais frágil da população, suprindo uma demanda ligada à saúde e ao perfil etário. Não fosse essa modalidade de transferência de renda, certamente, os efeitos da crise seriam ainda mais perversos. 
Figura 17. Goiás, total e valor dos benefícios da Aposentadoria Rural e dos Benefícios de Prestação Continuada, 2019

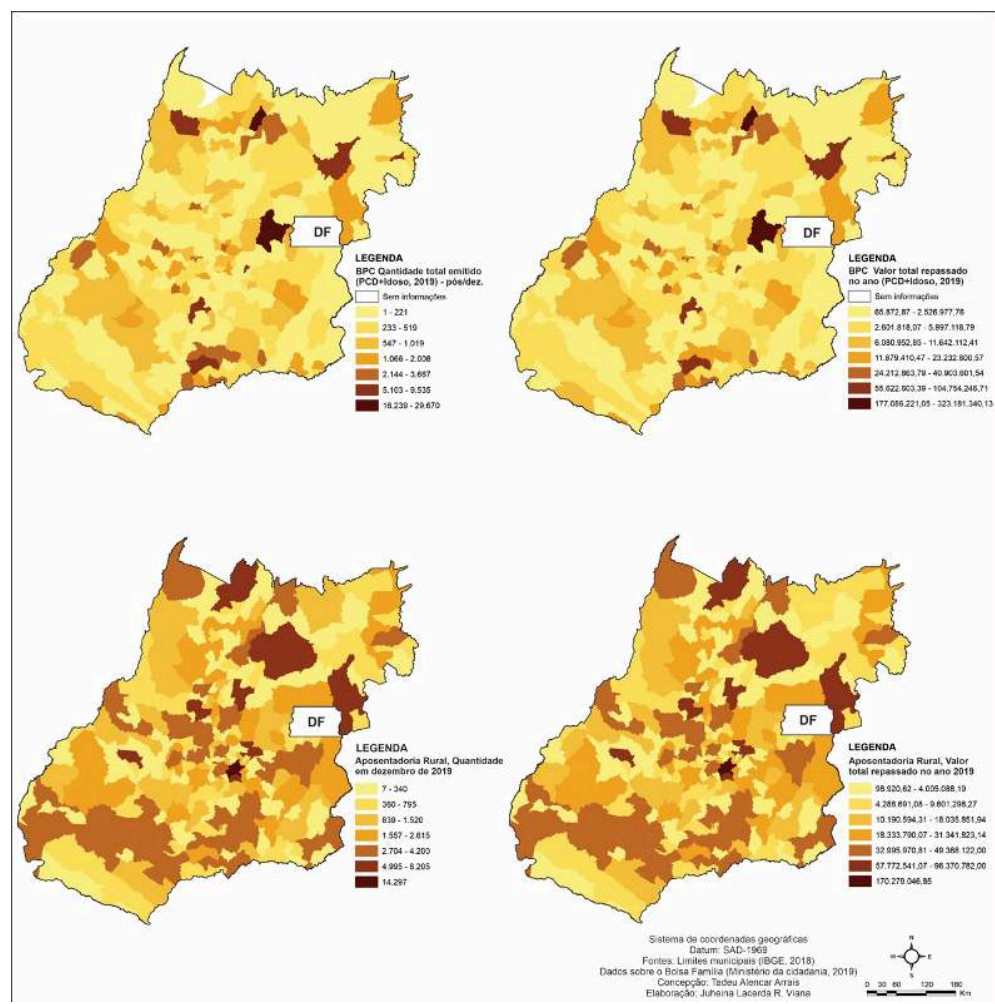

Fonte: INSS (2019) 
Figura 18. Goiás, total e valor dos benefícios de Aposentadoria e Pensão emitidos, dezembro de 2019

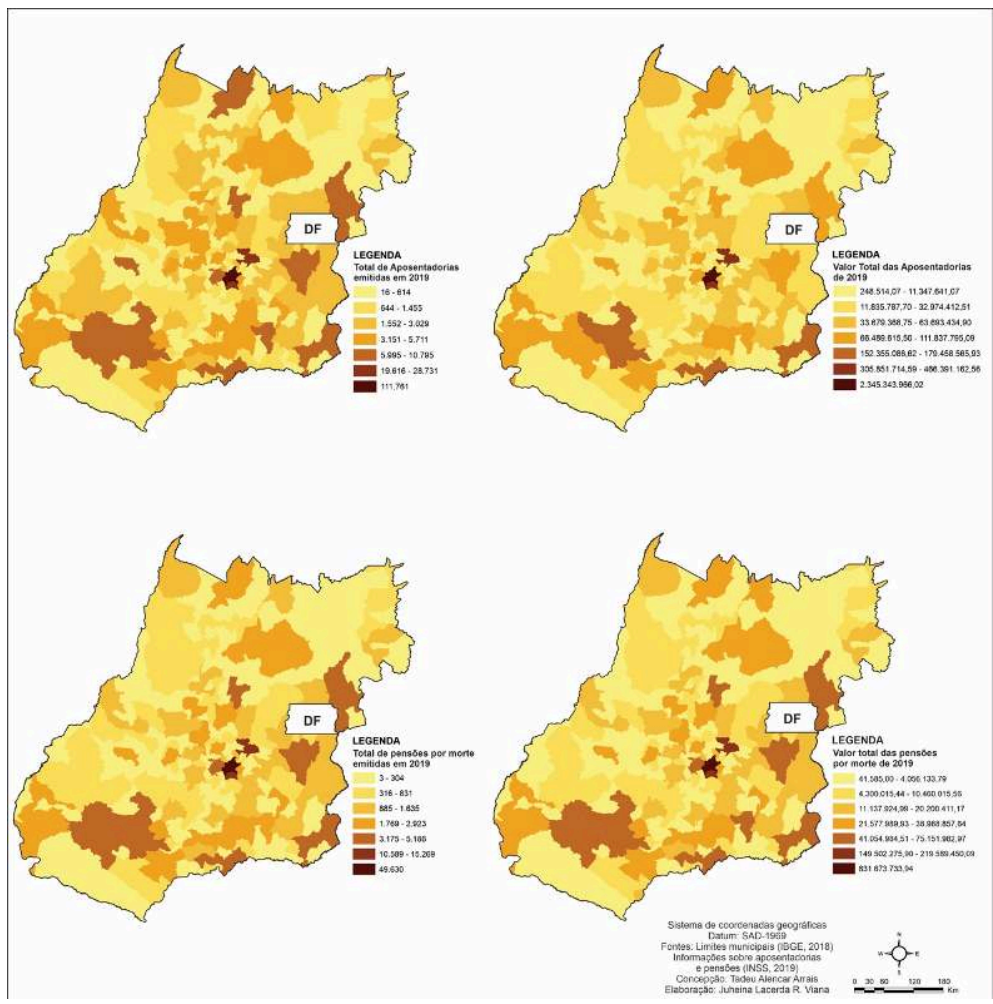

Fonte: INSS (2019)

\section{Perfil regional da renda das aposentadorias e pensões}

As aposentadorias e pensões do INSS, equivalentes a 702.624 benefícios, em 2019, que contemplam o segundo bloco de maior massa de rendimento, perdendo apenas para os empregos formais. São 10,6 bilhões de massa de rendimentos distribuídos nos 246 municípios goianos com valor médio de $\mathrm{R} \$ 1.313,82$ para as aposentadorias e $\mathrm{R} \$$ $1.183,00$ para as pensões. A renda da aposentadoria do INSS guarda características singulares. A primeira resulta do seu inequívoco vínculo com mundo do trabalho formal e a segunda refere-se ao processo de reverberação da renda. Não raro, em situações de desemprego, os aposentados transformam-se em arrimos de família.

É preciso recordar, no contexto do discurso da austeridade fiscal, que a reforma da previdência ampliou a idade e o tempo de contribuição, adiando, para muitos contribuintes, o tempo para aposentadoria. É exatamente nestes termos que é necessário frisar que a defesa constitucional do emprego formal em tempos de pandemia é, mais do que nunca, política pública garantidora de fluxo de renda àqueles que tiveram a expectativa de previdência postergada. Em longo prazo, os efeitos da não reposição destes postos de trabalho significará, ao conjunto dos municípios com menor peso demográfico, maior demanda por políticas de transferência direta e indireta de renda. 
Figura 19. Receitas, despesas e resultado financeiro do RPPS municipal e estadual, julho de 2019

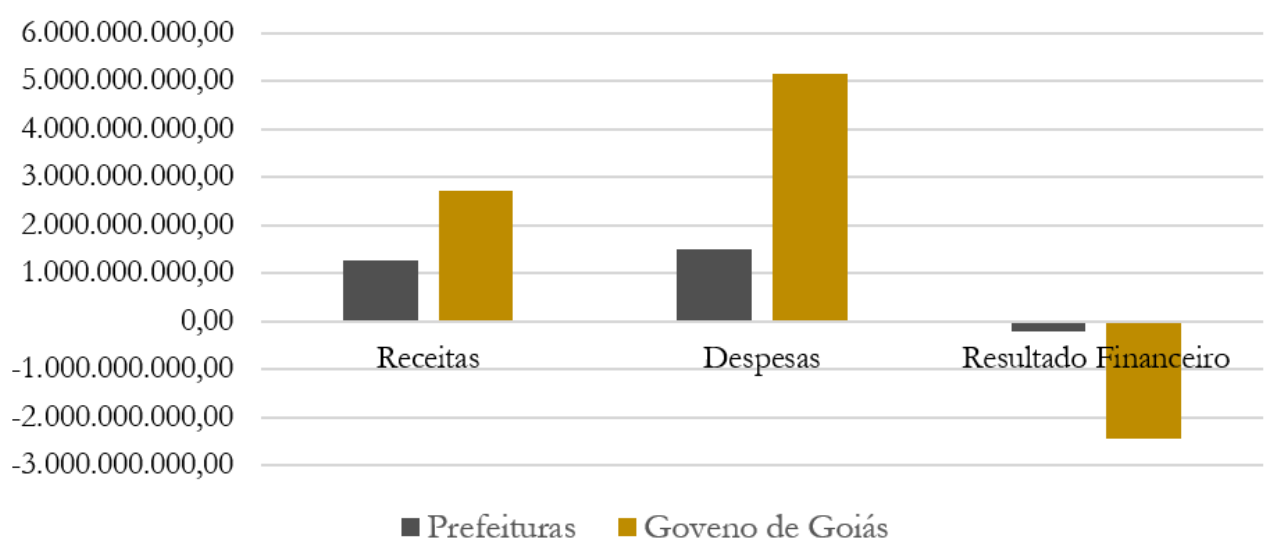

Fonte: INSS (2020)

30 É necessário pensar, ainda, as implicações da renda dos RPPS (Regimes Próprios de Previdência Social) municipais e do estado. Dos 246 municípios goianos, 170 possuem RPPS. Desse total, 77 apresentaram, em 2019, déficit. No estado, o déficit, no mesmo período, foi de 2,4 bilhões de reais (INSS, 2020). Estamos próximos de um colapso do sistema, e o momento de crise piora devido a redução da arrecadação, reforçando a imperativa necessidade de negociação da dívida pública com a União.

\section{Estratégias para efetivação das transferências de renda direta e indireta}

31 O conjunto de ações relativas às transferências de renda direta, devido ao volume do aporte financeiro e a facilidade burocrática, deve ser executado, prioritariamente, na ESCALA FEDERAL. É oportuno, nessa escala:

Garantir os níveis de transferências constitucionais federais (Fundo de Participação dos Municípios - FPM e Fundo de Manutenção e Desenvolvimento da Educação Básica FUNDEB) para todos os municípios goianos. Esse fato é imprescindível, uma vez que garante, especialmente nos munícios abaixo de 50 mil habitantes, a massa salarial mensal vinculada ao executivo municipal. Nos municípios desse corte demográfico, com mais ênfase, as transferências constitucionais federais permitem as prefeituras arcarem com despesas de custeio e folha de pagamento. Não garantir os níveis de transferências constitucionais durante a crise terá resultados catastróficos para a economias de dezenas de municípios goianos. Não adianta destinar vultosos recursos para financiamento da produção sem garantir, ao mesmo tempo, o padrão histórico de transferências constitucionais para os municípios. 
Figura 20. Total de transferências constitucionais federais (FPM e FUNDEB) para os municípios goianos, em milhões de R\$

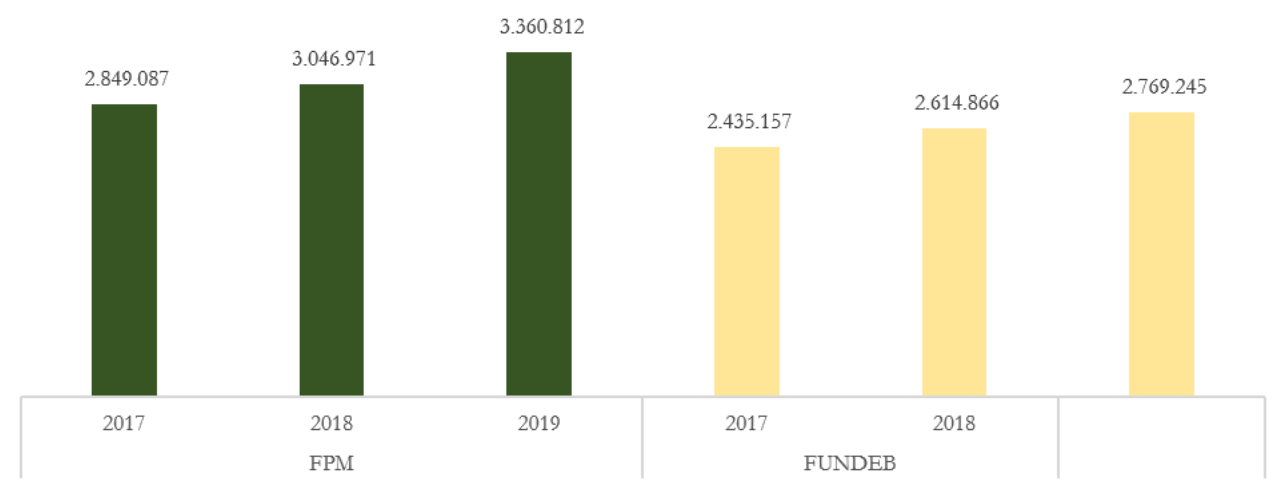

Fonte: Tesouro Nacional (2019)

Suplementar, até o janeiro de 2021, os benefícios do Bolsa Família até o limite, nos municípios abaixo de 50 mil habitantes, de $\mathrm{R} \$ 600,00$ por família. Nos municípios acima de 50 mil habitantes e fora dos contextos metropolitanos, no valor de $\mathrm{R} \$ 800,00$ por família. Por fim, nos municípios metropolitanos, $\mathrm{R} \$ 1.000,00$ por família. Ao considerar a realidade da rede urbana, somada aos distintos custos de vida, também regionais, otimiza-se a alocação dos recursos.

Destinar, para os municípios em contextos metropolitanos, recursos para utilização exclusiva de transferência de renda monetária para trabalhadores informais, em condições de vulnerabilidade, com duração de dois meses, prorrogáveis por igual período. É imprescindível que a operacionalização do programa seja centrada na ESCALA MUNICIPAL, já que se espera dos gestores maior conhecimento da dinâmica do mercado informal local.

Figura 21. Total de famílias vulneráveis em Goiás, RMG e RIDE, por faixa de rendimento, 2019

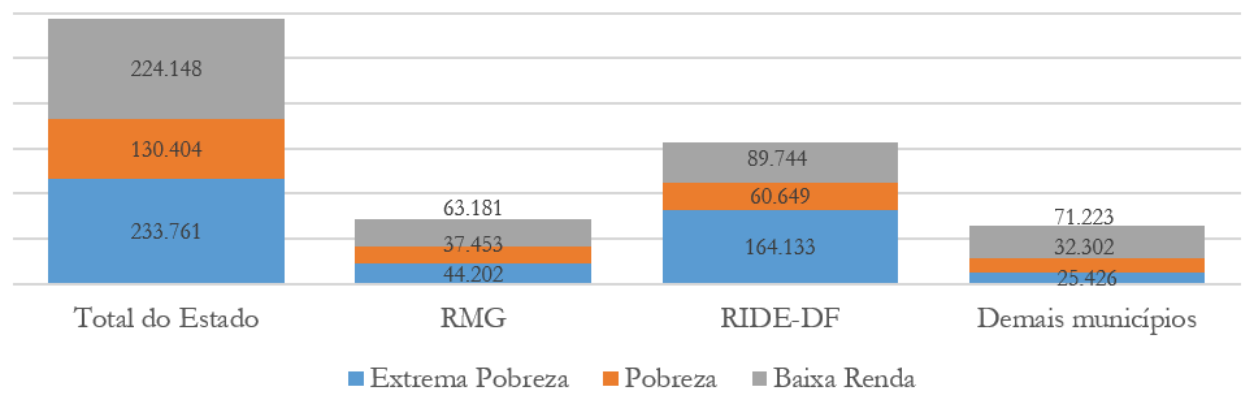

Fonte: MDS (2019)

Extrema Pobreza - Famílias com renda mensal de até R\$ 89,00 por pessoa. Pobreza - Famílias com renda mensal de R\$ 89,01 e R\$ 178,00 por pessoa. Baixa Renda - renda familiar de até meio salário mínimo por pessoa, ou até três salários mínimos no total.

Destravar os processos de concessão já demandados de benefícios rurais e urbanos do INSS, assim como os benefícios de prestação continuada. Essa medida, eficaz em diferentes contextos demográficos, causaria impacto positivo na vida de idosos pobres e portadores de deficiência. 
Figura 22. Goiás e Distrito Federal, população acima de 60 anos estimada para 2020, total de leitos para cada 1000 habitantes e total de leitos de UTI em 2019 e ocorrências de casos e óbitos de Coronavírus

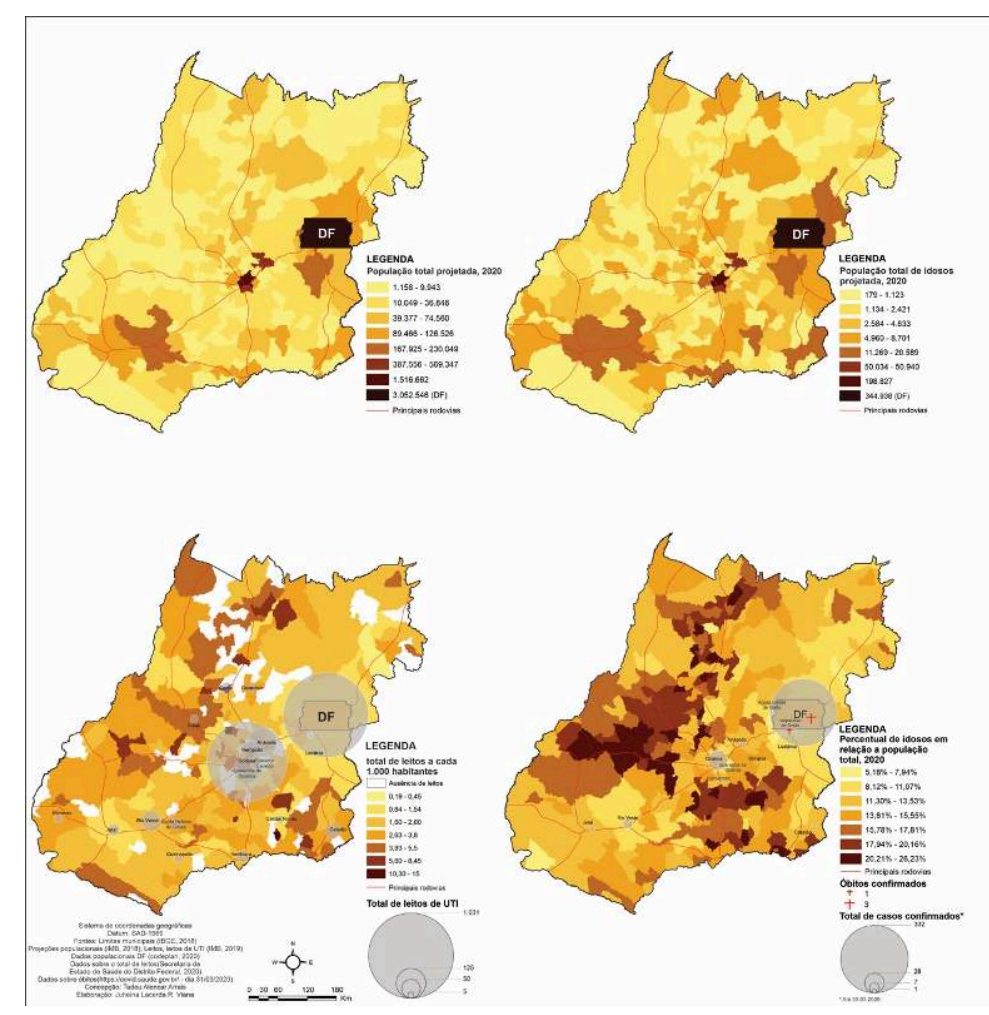

Fonte: IMB (2019), IBGE (2019), DATA-SUS (2019), SINDSAÚDE-DF (2019), Ministério da Saúde (2020)

*O total de ocorrências e de óbito do Coronavírus refere-se ao dia 31/03/2020. O total de UTIs não contempla as ampliações emergenciais relativas ao ano de 2020.

Entre o conjunto de ações relativas às transferências de renda indireta, estimulada na ESCALA ESTADUAL, em associação com os governos municipais, potencializando políticas pré-existentes e criando novas em ocasião emergencial, pode-se citar:

Execução de um programa emergencial de distribuição de cestas básicas regionais, articulando estratégias de compra de itens produzidos regionalmente, o que estimularia a geração de renda via geração de emprego - tal programa se enquadraria na estratégia de transferência de renda indireta. Para isso, poderia ser utilizado o desenho institucional dos programas de compras institucionais da agricultura familiar como o Programa de Aquisição de Alimentos (PAA), operacionalizado pela Companhia Nacional de Abastecimento (CONAB) e o Programa Nacional de Alimentação Escolar (PNAE), gerenciado a partir dos recursos provenientes do Fundo Nacional de Desenvolvimento da Educação (FNDE). A articulação com agricultores regionais permitirá incremento de renda e geração de emprego. 0 aproveitamento do desenho institucional das políticas de compras institucionais da agricultura familiar fortaleceria a segurança alimentar e nutricional no campo e na cidade. No campo, os agricultores familiares teriam com o fornecimento de cestas básicas, a manutenção e ampliação de canais de comercialização que estão sendo comprometidos em virtude da suspensão das feiras livres e demais formas de acesso ao consumidor final. Em função das políticas de aquisição de alimentos, empreendidas pelo Governo Federal, estes agricultores se encontram organizados em associações e cooperativas de produtores, o que facilitaria 
sobremaneira a operacionalização tanto da oferta dos alimentos quanto o pagamento dos subsídios pelo Governo Estadual.

Garantir os níveis de transferências constitucional da cota municipal do Imposto sobre Circulação de Mercadorias e Serviços (ICMS) para todos os municípios goianos. Esse fato é imprescindível, uma vez que garante, especialmente nos municípios abaixo de 50 mil habitantes, a massa salarial mensal vinculada ao executivo municipal para saldar as despesas com a máquina pública. Como contrapartida, poderá ser exigido que o município aplique um percentual da cota do ICMS em programas de assistência social e saúde da família.

Figura 23. Pirâmide etária da população projetada para 2020, com Goiás à esquerda e Distrito Federal à direita

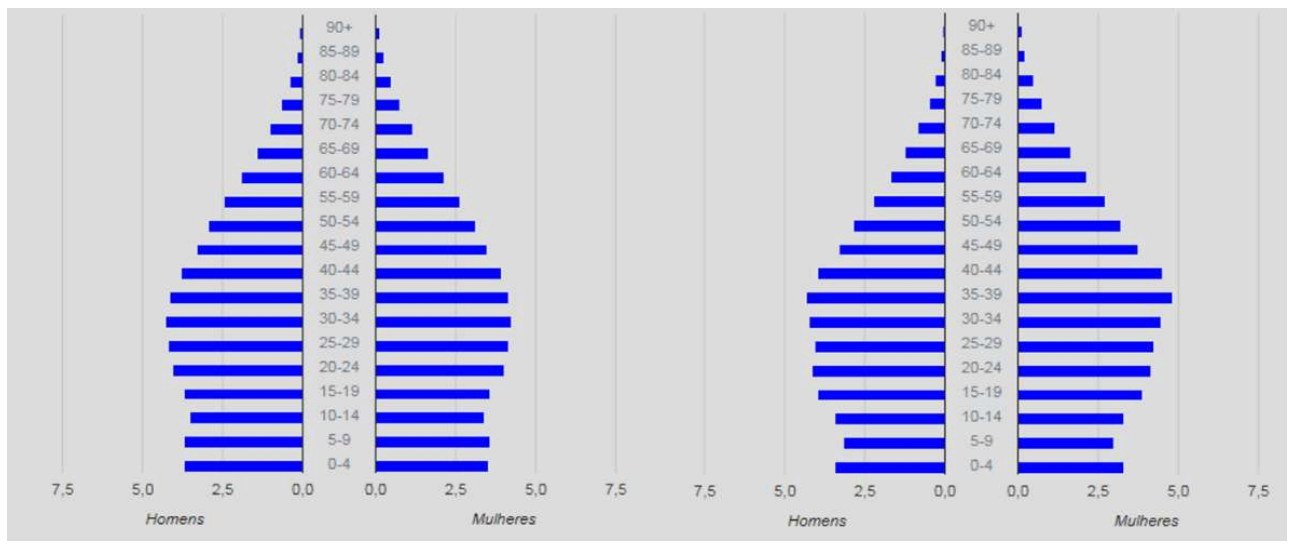

Fonte: IBGE (2019)

Essas estratégias devem considerar três questões:

A primeira questão: priorização do Entorno do Distrito Federal e da Região Metropolitana de Goiânia. Essas duas regiões concentram os chamados Aglomerados Subnormais, que reúnem, grosso modo, três características: 1) elevada densidade de ocupação domiciliar; 2) déficit na oferta de infraestrutura, especialmente serviços urbanos públicos e saneamento; 3) alta integração de movimento pendular entre os distintos núcleos urbanos. No caso do Entorno de Distrito Federal, como indicado na Figura 22, ainda há o complicador da concentração da população acima de 60 anos no Distrito Federal que atingiu, em 2020, segundo projeções, 344.938 habitantes. Até 31/03/2020 havia 332 casos de Coronavírus confirmados no Distrito Federal. A integração de Goiás com o DF ocorre, predominantemente, pelos vetores rodoviários (BR-060, BR-070, BR-020, BR-040, além das rodovias estaduais) a partir dos quais, também, registram-se fluxos cotidianos com as regiões Norte, Nordeste e Sudeste de Goiás. O polo concentrador de empregos (DF) tem potencial inequívoco para transformar-se em um polo disseminador do Coronavírus, uma vez que o vírus não respeita fronteiras administrativas. Como complicadores, essas regiões (RMG e Entorno do DF) concentram empregos formais - na área de serviços e comércio - e os empregos informais, característicos da economia urbana metropolitana, dois setores mais sensíveis em relação ao impacto do desemprego. A fragilidade dessas regiões também se traduz na paisagem urbana, bastando para isso notar que cidades como Goiânia concentram elevado número de pessoas em situação de rua ${ }^{4}$. Nessas regiões, a estratégia de isolamento social se torna mais difícil, dada a fragilidade da renda e das 
demandas na assistência social. Por outro lado, nos municípios das regiões Oeste e Noroeste, especialmente, encontram-se as maiores concentrações relativas da população idosa, o que exigirá, considerando o contexto regional, diferentes estratégias de isolamento social.

A segunda questão: identificação dos grupos prioritários para receberem os aportes de programas de transferência de renda direta e indireta. Aqui não há segredo, já que o Governo Federal dispõe dos instrumentos burocráticos e dos operadores financeiros para atender as demandas. A centralização das ações do Cadastro Único é fundamental, pois permite associar agilidade na burocracia, reduzindo, portanto, os custos operacionais. O Cadastro Único abarca tanto indivíduos sem renda, quanto indivíduos com renda formal e também com renda informal. O Cadastro Único e a estrutura burocrática formada pelos CRAS e CREAS municipais, entre outras unidades de acolhimento social, são para estabelecer parâmetros de focalização.

42 A terceira questão: necessidade de articulação institucional. Essa dimensão, aparentemente mais simples, tem sido apresentada como aquela mais complexa. Estados e municípios têm apresentado disposição para essa articulação. No entanto, dada a centralidade dos recursos, existem muitas limitações das escalas estaduais e municipais. O momento, único na história da nossa jovem República, exige uma carga de solidariedade federativa, própria de regimes democráticos e comprometidos com o bem-estar da população.

\section{Conclusão}

43 No Brasil, o primeiro registro de Coronavírus ocorreu em 26 de fevereiro no hospital Albert Einstein, em São Paulo, em um paciente recém regressado da Itália, ao passo que o primeiro óbito decorrente da infecção foi confirmado em 17 de março. Em Goiás, o primeiro óbito ocorreu em 26 de março, na cidade de Luziânia, localizada no entorno do Distrito Federal.

Embora tenha reconhecido a transmissão comunitária no dia 20 de março (AGÊNCIA BRASIL, 2020), o Governo Federal relutou e tergiversou durante muito tempo para assumir o seu protagonismo na conciliação entre as medidas de controle epidemiológico e a as ações econômicas para mitigar o efeito da pandemia no Brasil. Em um país que já assiste severas restrições nos investimentos públicos, como indicado por Tavares (2019), em função do Novo Ajuste Fiscal, não poderia ser distinto o quadro que se acompanha no presente momento.

o Coronavírus, do ponto de vista do ambiente econômico e social, encontrou, no Brasil, um celeiro para sua propagação. Engessado pelos compromissos de austeridade fiscal, o imobilismo do Governo Federal tem subestimado os efeitos do quadro social manifestado nos diferentes lugares pelo país afora. $O$ isolamento social, que se constitui na principal estratégia de prevenção da propagação da doença está seriamente comprometido pelo efetivo de brasileiros que se encontra na condição de desempregados e/ou trabalhadores informais. Neste sentido, do ponto de vista da "divisão de classes", assiste-se no país, de um lado, uma fração da sociedade consciente dos riscos relacionados à pandemia e "enclausurada" em suas residências com a manutenção de sua capacidade de consumo (encontram-se neste grupo os trabalhadores formais com relativa estabilidade de emprego e os servidores públicos das diferentes esferas do etc.); e, por outro lado, uma fração majoritária que está 
submetida à própria sorte, deslocando-se no transporte coletivo abarrotado com destino aos seus locais de trabalho formal e/ou informal. Para estes há o risco permanente do desemprego e a ausência da renda para a reprodução das condições de reprodução da vida de suas famílias.

Como se não bastasse a condição de desemprego e informalidade, nos grandes centros se concentram os déficits de moradia e saneamento básico que impossibilitariam as condições mínimas de proteção necessárias para a prevenção da pandemia. Engana-se quem acredita que esses déficits são "privilégios" dos "bairros de lata" que se proliferam em grandes aglomerações urbanas do Continente Africano e Sul da Ásia (DAVIS, 2020). Para isto, basta conhecer as palafitas dos aglomerados urbanos ao longo dos rios da região Norte ou nas regiões litorâneas do Sudeste ou nordeste do país. No Brasil, $48 \%$ da população vive em áreas sem coleta de esgoto e 35 milhões de pessoas não têm acesso à água tratada (RÁDIO SENADO, 2019).

O desencontro das ações do Governo Federal e até mesmo as posições divergentes entre o Chefe do Executivo e o seu Ministro da saúde, inaugurou algo inédito na história do federalismo brasileiro: governadores dos 26 estados e do Distrito Federal têm envidado esforços para a contenção da pandemia na escala dos seus territórios de ação. No último dia 25 de março, os 27 governadores estiveram reunidos, via videoconferência, com o presidente da câmara dos deputados, visando acelerar medidas de enfrentamento da crise epidêmica e econômica (Valor, 2020).

Diante deste cenário, que se viu a necessidade de apresentar este documento, para subsidiar a construção de um Plano em Caráter Emergencial para o estado de Goiás, reunindo estratégias econômicas para enfrentar este momento circunstancial provocado pelo Coronavírus. Experiências distintas pelo mundo afora têm demonstrado a necessidade de uma forte intervenção dos Estados-Nações para contornar os efeitos da pandemia para a manutenção da vida das pessoas e, por conseguinte mitigar os efeitos econômicos decorrentes do período de arrefecimento da produção, circulação e consumo da população mundial. 0 capital privado tem demonstrado a sua incapacidade de contornar os efeitos deletérios de uma pandemia: nos Estados Unidos, 15 dos 18 laboratórios farmacêuticos deixaram de investir na pesquisa e desenvolvimento de antibióticos e antivirais, mantendo suas atenções voltadas essencialmente para "doenças rentáveis" como a hipertensão. "Uma vacina universal contra a gripe - isto é, uma vacina que visa as partes imutáveis das proteínas de superfície do vírus - tem sido uma possibilidade durante décadas, mas nunca considerada lucrativa o suficiente para ser uma prioridade". (DAVIS, 2020).

Ciente das dificuldades que se apresentam no horizonte, cabe à autoridade governamental do estado de Goiás mobilizar e operacionalizar estratégias eficientes de gestão dos recursos públicos que possam conciliar medidas de proteção à saúde do povo goiano, ao mesmo tempo que garantam condições dignas de reprodução da vida de suas famílias. Quiçá possamos superar juntos a angústia inerente ao excerto do texto a seguir, elaborado por um coletivo de pensadores-ativistas chineses:

Este momento, embora cheio de medo, fez com que todos fizessem perguntas profundas ao mesmo tempo: $\mathrm{O}$ que vai acontecer comigo? Meus filhos, família e amigos? Teremos comida suficiente? Eu serei pago? Vou conseguir pagar o aluguel? Quem é responsável por tudo isso? [...] A quarentena, então, é como uma greve oca de suas características comunais, mas, no entanto, capaz de causar um choque profundo à psique e à economia. Somente esse fato já a torna digna de reflexão. (A FITA, 2020). 
51 Sabemos que nosso futuro está franqueado para a ciência, traduzida na miríade de profissionais e pesquisadores da área da saúde que estão, diuturnamente, empenhados em oferecer soluções e alternativas para a superação da crise. Esse relatório deve ser entendido como uma modesta contribuição de profissionais da área do desenvolvimento regional ligados ao Instituto de Estudos Socioambientais, da Universidade Federal de Goiás, que, cientes da responsabilidade histórica da comunidade acadêmica, desejam contribuir, enquanto aguardam em quarentena, com o debate sobre as alternativas políticas para minimizar os efeitos da crise no estado de Goiás.

Saúde Para Todos!

\section{BIBLIOGRAFIA}

A FITA. Outras Fitas: Contágio Social - coronavírus, China, capitalismo tardio e o 'mundo natural'. 29 de fev. 2020. Disponível em: http://afita.com.br/outras-fitas-contagio-social-coronavirus-chinacapitalismo-tardio-e-o-mundo-natural/ Acesso em 10 de mar. 2020.

AGÊNCIA BRASIL. Covid-19: governo declara transmissão comunitária em todo o país. Brasília: DF, 20 de mar. 2020. Disponível em: https://agenciabrasil.ebc.com.br/saude/noticia/2020-03/covid-19governo-declara-transmissao-comunitaria-em-todo-o-pais Acesso em: 30 de mar. 2020.

ALENCAR, Diego Pinheiro. A Questão Social e as Transferências De Renda: o Programa Bolsa Família em municípios goianos. Tese (Doutorado em Geografia) Instituto de Estudos Socioambientais, Universidade Federal de Goiás, Goiânia, 2020.

ARRAIS, T. A. DESIGUALDADE DE RENDA, EMPREGO PÚBLICO E TRANSFERENCIAS DE RENDA NO BRASIL CONTEMPORÂNEO. Mercator (Fortaleza) [online]. 2019, vol.18, e18008. Epub May 30, 2019. ISSN 1676-8329. https://doi.org/10.4215/rm2019.e18008.

ARRAIS, Tadeu Alencar. O Bolsa Família e a tradução regional da questão social. Rev. Inst. Estud. Bras. [online]. 2016, n.65, pp.200-226. ISSN 0020-3874. https://doi.org/10.11606/issn. 2316-901x.v0i65p200-226.

BEVERIDGE, W. H. O Plano Beveridge. Rio de Janeiro: Livraria José Olympio, 1943.

BIHR. Alain. França: pela socialização do aparato de saúde. In: DAVIS, Mike. et al: Coronavírus e a luta de classes. Terra sem Amos: Brasil, 2020. 48p.

BRASIL. Lei Complementar № 11, de 25 de março de 1971. Brasília: Casa Civil, 1971. Disponível em http://www.planalto.gov.br/ccivil_03/LEIS/LCP/Lcp11.htm. Acessado em 31/03/2020.

BRASIL. Lei № 6.179, de 11 de dezembro de 1974. Brasília: Casa Civil, 1974. Disponível em: http:// www.planalto.gov.br/ccivil_03/LEIS/L6179.htm. Acessado em 31/03/2020.

BRASIL. Medida Provisória № 132, de 20 de outubro de 2003. Brasília: Casa Civil, 2003. Disponível em: http://www.planalto.gov.br/ccivil_03/MPV/Antigas_2003/132.htm 
Censo Indica que... https://www.opopular.com.br/noticias/cidades/censo-indica-que-42-dosmoradores-de-rua-de-goi\%C3\%A2nia-est\%C3\%A3o-nessa-situa\%C3\%A7\%C3\%A3o-h\%C3\%A1-maisde-2-anos-1.1951110\#_=

Disponível em:

http://www.imb.go.gov.br/index.php? option=com_content\&view=category\&layout=blog\&id=225\&Itemid=188 acesso em 30/03/20 as $17: 15$

DAVIS, Mike. A crise do coronavírus é um monstro alimentado pelo capitalismo. In:

DAVIS, Mike. et al: Coronavírus e a luta de classes. Terra sem Amos: Brasil, 2020. 48p.

GALBRAITH, John Kenneth. A economia e o objetivo público. São Paulo: Martins, 1975.

http://www.imb.go.gov.br/estatisticas/produtos/proje\%C3\%A7\%C3\%A3o-da-

popula\%C3\%A7\%C3\%A3o/proje\%C3\%A7\%C3\%A3o-da-popula\%C3\%A7\%C3\%A3o-goiana-2011-2020idade-e-sexo.html

https://biblioteca.ibge.gov.br/visualizacao/livros/liv101629.pdf

IBGE. Censo demográfico 2010. Aglomerados subnormais. Rio de Janeiro, IBGE, 2010.

IBGE. Estimativas populacionais. Rio de Janeiro: IBGE, 2017a. Disponível em: <https:// www.ibge.gov.br/estatisticas-novoportal/sociais/populacao/9103-estimativas-depopulacao.html?=\&t=o-que-e>. Acesso em: 28/03/2020.

IBGE. Instituto Brasileiro de Geografia e Estatística. Síntese dos Indicadores Sociais. Rio de Janeiro: IBGE, 2018. Disponível em: <https://www.ibge.gov.br/estatisticas-novoportal/sociais/educacao/ 9221-sintese-de-indicadores-sociais.html?=\&t=o-que-e>. Acesso em: 15/05/2018.

IMB. A Vulnerabilidade Social nos Municípios Goianos. In: http://www.imb.go.gov.br/files/docs/ publicacoes/estudos/2018/a-vulnerabilidade-social-dos-municipios-goianos.pdf

IMB. Instituto Mauro Borges. Estatísticas municipais. Goiânia: IMB, 2019. Disponível em http:// www.imb.go.gov.br/estatisticas/produtos/proje\%C3\%A7\%C3\%A3o-da-popula\%C3\%A7\%C3\%A3o/ proje\%C3\%A7\%C3\%A3o-da-popula\%C3\%A7\%C3\%A3o-goiana-2011-2020-idade-e-sexo.html Acessado em 29/03/2020.

IMB. Projeção da População 2011-2020. 2018

MDS. Ministério do Desenvolvimento Social. Relatório de Programas e Ações (v. 2017). Brasília: MDS, 2019. Disponível em: https://aplicacoes.mds.gov.br/sagi/ri/relatorios/mds/? localizaDivisao=\%C3\%81guas + Lindas + de + Goi\%C3\%A1s\&codigo=52\&aM=0 Acessado em 29/03/2020.

MTE. Ministério do Trabalho e Emprego. Relatório anual de informações sociais. Brasília: MTE, 2016.

NERI, Marcelo Cortes; VAZ, Fábio Monteiro; SOUZA, P. Herculano G. Efeitos macroeconômicos do programa Bolsa Família: uma análise comparativa das transferências sociais. In: CAMPELLO, Tereza; NERI, Marcelo Côrtes (Org.). Programa Bolsa Família: uma década de inclusão e cidadania. Brasília, Ipea, 2013.

OMS. Organização Mundial de Saúde. Folha informativa - COVID-19 (doença causada pelo novo Coronavírus. OPAS: Brasil, 2020. Disponível em: https://www.paho.org/bra/index.php? option=com_content\&view=article\&id=6101:covid19\&Itemid=875 Acesso em: 30 de mar. 2020 PAINE, T. Justiça agrária. In: SUPLICY, E.M. Renda de cidadania: a saída é pela porta. São Paulo: Cortez, 2002. 
PIKETTY, Thomas. O capital no século XXI. Rio de Janeiro: Intrínseca, 2014.

POP RUA 2019: Censo e perfil da população de rua em Goiânia e Pesquisa sobre o trabalho realizado nas ruas de Goiânia: mapeamento dos/as trabalhadores/as de rua de Goiânia. UFG: FCS, 2019. Disponível em: https://www12.goiania.go.gov.br/censo-levanta-perfil-da-populacao-de-rua-na-capital/. Acesso em 01 de abr. 2020.

RÁDIO SENADO. Onde fica o banheiro? - o saneamento básico no Brasil. Brasília: Senado Federal, 2019. Disponível em https://www12.senado.leg.br/radio/1/reportagem-especial/onde-fica-obanheiro-2013-o-saneamento-basico-no-brasil. Acesso em: 30 de mar. 2020.

SEN, Amartya. Desenvolvimento como liberdade. São Paulo: Cia das Letras, 2000.

SENADO FEDERAL. Projeto de Lei № 873 de 2020. Brasília: Senado Federal, 2020. Disponível em: https://www25.senado.leg.br/web/atividade/materias/-/materia/141174. Acessado em: $30 / 03 / 2020$.

SILVA, Maria Ozarina da Silva e. Caracterização e problematização dos Programas de Transferência de renda Condicionada (PTRC) na América Latina e Caribe. In: SILVA, Maria Ozarina da Silva e Silva. Programas de Transferência de Renda na América Latina e Caribe. São Paulo: Cortez, 2017.

SOCIAL SECURITY. The Social Security Act (Act of August 14, 1935) [H. R. 7260]. Disponível em: <https://www.ssa.gov/history/35act.html>. Acesso em: 16 fev. 2018.

TESOURO NACIONAL. Transferências Constitucionais. Brasília: secretaria do tesouro nacional, 2019. Disponível em:sisweb.tesouro.gov.br. Acessado em 29/03/2020.

VALOR. 27 governadores reúnem-se com Maia por teleconferência. Brasília: 25 de mar. 2020. Disponível em: https://valorinveste.globo.com/mercados/brasil-e-politica/noticia/2020/03/25/27governadores-renem-se-com-maia-por-teleconferncia.ghtml Acesso em 30 de mar. 2020

\section{NOTAS}

1. Na pátria de John Maynard Keynes, no ambiente da Segunda Guerra Mundial, William Beveridge (Beveridge, 1943) enviou para o parlamento o Relatório Sobre o Seguro Social e Serviços Afins. O propósito do economista e reformista social britânico era combater a pobreza e o desemprego a partir de um conjunto de intervenções estatais, a exemplo das transferências de renda, especialmente, para crianças e idosos. Antes disso, em 1935, nos Estados Unidos, surgiu o The Social Security Act (Social Security, 1935, on-line), prevendo um conjunto de medidas na escala federal para o combate à pobreza, com foco em idosos, crianças, desempregados e incapacitados.

2. Não é objetivo desse relatório, em função do tempo, fazer incursões teóricas sobre a temática das transferências de renda, bastando para isso lembrar que esse debate, teoricamente, remonta ao século XVI, com o filósofo Thomas Paine (2002). Na Europa, especialmente após os Gloriosos Trinta, o debate sobre o papel do Estado social ganhou centralidade, uma vez que o acelerado crescimento do pós-guerra, expresso nos baixos níveis de desemprego e na universalização dos serviços públicos, entrara em declínio. A universalização dos serviços públicos e os direitos sociais foram colocados em xeque. No entanto, a universalização dos serviços públicos não resume as diferentes redes de proteção social. Os chamados Programas de Transferências de Renda são um exemplo. $\mathrm{Na}$ América Latina, como indicado em pesquisa de Silva, programas dessa natureza são 
registrados em diferentes países, a exemplo de Honduras (1990), Colômbia (2000), México (2000), Chile (2000) e mais recentemente Guatemala (2012).

3. Não foram incluídas as rendas dos Regimes Próprios de Previdência Social do Estado e dos municípios, além dos empregos informais. Um indivíduo pode desenvolver atividade produtiva formal e manter, como complementação de renda, trabalhos informais. O mesmo ocorre com aposentados e pensionistas quando agregam outros tipos de rendimento, a exemplo de trabalhos informais e/ou formais. No serviço público, especialmente no magistério, é comum vínculo simultâneo com o Estado e as prefeituras ou entre os entes privados e os entes públicos. As pensões, frequentemente, implicam em acúmulo de benefícios para um dos cônjuges e/ou filhos que dispõe de outras fontes de renda. Quanto às transferências de renda, também é possível acúmulo com o trabalho formal e/ou informal, desde que o valor per capita familiar não atinja o teto do rendimento que caracteriza a cessão do benefício.

4. Conforme o POP Rua 2019: Censo e Perfil da população de rua em Goiânia e Pesquisa sobre o trabalho realizado nas ruas de Goiânia, há 353 pessoas em situação de rua na capital goiana.

\section{RESUMOS}

As políticas de transferência de renda (direta e indireta) são instrumentos eficazes para arrefecer os efeitos econômicos da crise pandêmica decorrente do novo Coronavírus. Isso demanda uma ação conjunta e articulada entre os entes federados (União, Estados e Municípios) e sua eficácia está atrelada a capacidade de priorizar os grupos e os espaços mais vulneráveis. A urgência da situação demanda a construção de estratégias políticas e econômicas para garantir a renda mínima, primeiro, para a parcela da população mais vulnerável e, segundo, para a parcela que, em função da crise, encontra-se, temporariamente, sem renda originária do trabalho formal e/ou informal. Em Goiás, as estratégias de ação devem considerar três aspectos fundamentais: a) o adensamento da rede urbana (entorno do distrito federal e Região Metropolitana de Goiânia; b) a diversidade produtiva regional e o perfil de emprego gerado (empregos formais e informais) e c) o perfil demográfico da população (correlação entre população idosa e capacidade suporte das Unidades de Terapia Intensiva). O reconhecimento destas particularidades deve permitir o planejamento estruturado para atravessar o período pandêmico com qualidade nos serviços de saúde e recuperação econômica a médio prazo.

Income transfer policies (direct and indirect) are effective instruments to mitigate the economic effects of the pandemic crisis resulting from the new Coronavirus. This demands a joint and articulated action between the federated entities (the Union, States, and Municipalities) and its effectiveness is linked to the ability to prioritize the most vulnerable groups and spaces. The situation's urgency demands political and economic strategies be made to guarantee the minimum income, first, for the portion of the most vulnerable population and, second, for the portion that, due to the crisis, is temporarily without original income from formal and/or informal work. In Goiás, strategies for action must consider three fundamental aspects: a) the densification of the urban network (surrounding the Federal District and the Metropolitan Region of Goiânia; b) the regional productive diversity and the employment profile generated (formal and informal jobs) and c) the demographic profile of the population (correlation between 
the elderly population and the support capacity of the Intensive Care Units). The recognition of these particularities should allow for structured planning to traverse the pandemic period with quality health services and economic recovery in the medium term.

Les politiques des transferts de revenus (direct et indirect) sont des outils efficaces en ce qui concerne à soulager les effets économiques de l'actuelle crise pandémique. Cela demande des actions articulées parmi les entités fédératives (Union, états, municipalités), et son efficacité est liée à la capacité de donner la priorité aux groupes et aux espaces les plus vulnérables. Le caractère urgent de la situation exige des stratégies politiques et économiques afin de garantir le revenu minimum à la population le plus vulnérable tout d'abord, et à ceux qu'ont perdu ses postes (formels or informels) à la suite. Dans l'état de Goiás, les stratégies d'action doivent considérer trois aspects essentiels : (i) la densité du réseau urbain (les alentours du Distrito Federal et la Région Métropolitaine de Goiânia) ; (ii) la diversité productive régionale et le profil de l'emploi (formels et informels); et (iii) le profil démographique (à savoir, le rapport entre la population âgée et la capacité des unités de soins intensifs). La reconnaissance de ces aspects doit garantir la qualité des services de santé, ainsi que la récupération économique à moyen terme.

Las políticas de transferencia de ingresos (directos e indirectos) son instrumentos eficaces para mitigar los efectos económicos de la crisis de la pandemia derivada del nuevo Coronavirus. Esto demanda de una acción conjunta y articulada entre los entes federales (Unión, Estados y Municipios) y su eficacia está ligada a la capacidad de priorizar los grupos y espacios más vulnerables. La urgencia de la situación demanda de una construcción de estrategias políticas y económicas para garantizar la renta básica/mínima. Primero, para la porción de la población mas vulnerable y segundo para el porcentaje de la población que, gracias a la crisis, se encuentra temporalmente sin los ingresos originados del trabajo formal e/o informal. En Goiás, los planes de acción deben contemplar tres aspectos fundamentales: a) la densificación de la red urbana (alrededor del distrito federal y de la Región Metropolitana de Goiania); b) la diversidad productiva regional y el perfil de empleo generado (empleos formales e informales) y c) el perfil demográfico de la población (correlación entre las personas mayores y la capacidad de las Unidades de Cuidados Intensivos). El reconocimiento de estas características debe permitir una planeación estructurada para poder atravesar la pandemia con alta calidad en los servicios de salud y recuperación económica a mediano plazo.

\section{ÍNDICE}

Keywords: Income transfer; Regional diversity; Institutional articulation and social vulnerability; public politics; Goiás.

Palabras claves: transferencia de ingresos; diversidad regional; articulación institucional y vulnerabilidad social; políticas publicas; Goiás.

Palavras-chave: Transferência de renda; Diversidade regional; Articulação institucional e Vulnerabilidade social; políticas públicas; Goiás.

Mots-clés: transfert de revenu; diversité régionale; articulation institutionnelle et vulnérabilité sociale ; politiques publiques ; Goiás. 


\section{AUTORES}

\section{TADEU ALENCAR ARRAIS}

Doutor em Geografia pela Universidade Federal Fluminense. Professor Associado do Instituto de Estudos Socioambientais (UFG) e Pesquisador do CNPq, 1D. E-mail: tadeuarraisufg@gmail.com

\section{ADRIANO RODRIGUES DE OLIVEIRA}

Doutor em Geografia pela Universidade Estadual Paulista. Professor Associado do Instituto de Estudos Socioambientais (UFG) e líder do Grupo de Estudos Trabalho, Território e Políticas Públicas (TRAPPU). E-mail: adriano.oliveira@ufg.br

\section{DIEGO PINHEIRO ALENCAR}

Doutor em Geografia pela Universidade Federal de Goiás. Professor do Instituto Federal Goiano, câmpus de Iporá-GO. E-mail: diego.alencar@ifgoiano.edu.br

\section{TATHIANA RODRIGUES SALGADO}

Doutora em Geografia pela Universidade Federal de Goiás. Professora da Universidade Estadual de Goiás (UEG) e editora da revista Élisée

\section{JUHEINA LACERDA VIANA}

Doutoranda em Geografia pela Universidade Federal de Goiás. E-mail:

juheinalacerda@hotmail.com

\section{AMANDA FERNANDES MIRANDA}

Graduanda em Geografia pela Universidade Federal de Goiás. E-mail: amandafm659g@gmail.com 